\title{
Fabrication and mechanical characterization of CFRP X-core sandwich panels
}

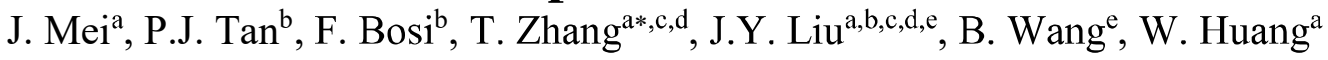

a School of Naval Architecture and Ocean Engineering, Huazhong University of Science and Technology, Wuhan 430074, PR China

${ }^{\mathrm{b}}$ Department of Mechanical Engineering, University College London, Torrington Place, London WC1E 7JE, UK

${ }^{\mathrm{c}}$ Hubei Key Laboratory of Naval Architecture and Ocean Engineering Hydrodynamics (HUST), Wuhan 430074, PR China

${ }^{\mathrm{d}}$ Collaborative Innovation Center for Advanced Ship and Deep-Sea Exploration (CISSE), Shanghai 200240, PR China

${ }^{\mathrm{e}}$ National Key Laboratory of Science and Technology on Advanced Composites in Special Environments, Harbin Institute of Technology, Harbin 150001, PR China

\begin{abstract}
A hot-press molding technique is developed to design and manufacture carbon fiber reinforced polymer (CFRP) X-core sandwich panels that allowed both the composite face sheets and its X-core to be simultaneously molded together. Compression tests were performed on the sandwich panels to assess the effects of relative density on its compressive properties and the failure mode that it develops. Analytical models were developed to predict the panel stiffness and strength; and a failure map of its deformation mode is generated based on the geometric parameters of the unit cell. Linear and nonlinear finite element analyses were performed to further investigate the effects of initial geometric imperfection and progressive damage on the response of the sandwich panels with different cell wall slenderness. Predictions from analytical and numerical models will be shown to be in good agreement with the experiments. The CFRP X-core sandwich panels will be shown to attain good compressive properties that are comparable to typical high strength cellular materials, which will be potentially useful for lightweighting applications.
\end{abstract}

Keywords: Carbon fiber; Mechanical properties; Analytical modelling; Mechanical testing; Failure mechanism map; Finite element analysis.

\section{Introduction}

Sandwich structures with various cellular cores, such as honeycomb [1], corrugated core [2], orthogrid core [3], periodic lattice [4-5] and foldcore [6], are widely used in structural engineering; in particular, in the aerospace industry, ships and bridge construction. In recent years, many ultra-light sandwich structures with different topological cores have been developed by using light-weight composite materials [7-9]. These structures showed superior mechanical performances with simultaneous weight reduction. Therefore, the enhancement of mechanical properties through core optimization and improved fabrication methods is an active area of research.

Lattice truss core sandwich structures with open-cell architectures made of composite materials are known to be weight-efficient. The compression properties of CFRP sandwich panels with pyramidal truss core fabricated by a snap-fitting method were tested by Finnegan et al. [10]. The pyramidal lattice core sandwich panel showed high specific compressive strength for low relative densities, due to its superior resistance to buckling when compared to common thin-wall cellular structures. George et al. [11] investigated the shear response of the same pyramidal truss core sandwich panel, and the specific shear properties were found to be comparable with those of CFRP honeycombs. Huang et al. [12-13] investigated the impulsive resistance of the composite lattice truss core sandwich structure. The energy absorption

\footnotetext{
* Corresponding author. at: School of Naval Architecture and Ocean Engineering, Huazhong University of Science and Technology, Wuhan 430074, PR China.

E-mail address: zhangt7666@hust.edu.cn (T.Zhang).
} 
efficiency of the composite lattice truss core sandwich structure was found to increase considerably by filling the foam. The advantage in specific strength and equivalent stiffness that the pyramidal truss core possesses among other cellular structures depends on its stretch-dominated architecture [14]. However, composite sandwich panel with orthogrid core, honeycomb or corrugated core represents valid alternatives to reduce the manufacturing cost while attaining high strength [15-17]. Jiang et al. [18] assessed the mechanical properties of composite orthogrid sandwich panels made by interlocking technology. This structure exhibited ductile deformation under compression and presented a specific energy absorption higher than metallic lattice truss core structures. An auxetic honeycomb with a negative Poisson's ratio was designed by Huang et al. [19]. The analytical in-plane tension modulus, shear modulus and Poisson's ratio were derived and validated by finite element (FE) method. The results indicated that the auxetic honeycomb had similar specific in-plane tensile modulus and Poisson's ratio compared with classical re-entrant hexagons, whereas it showed higher specific in-plane shear modulus. Wang et al. [20] investigated, both experimentally and theoretically, the compression properties of 3D double-arrow-head auxetic structure made of carbon fiber reinforced polymer. They showed that the negative Poisson's ratio and compressive modulus increased as the compressive strain increased. For the same geometry, they demonstrated that the composite auxetic structure outperformed the metallic one. Du et al. [21] fabricated a composite sandwich panel with a foldcore, investigating its compressive behavior through experiments and finite element method. In their work, the composite foldcore structure based on curved-crease origami presented a higher buckling load than the chevron origami foldcore. A fabrication method of an all-composite corrugated panel was presented by Kazemahvazi et al. [22], showing that the compressive strength was superior to that of aerospace-grade foams and honeycombs, while the shear strength was significantly lower. Hu et al. [23] manufactured corrugated lattice truss composite sandwich panels with an enlarged bonding area between the corrugated core and face sheets. They found that the bonding area significantly enhanced the shear strength of the sandwich structure, even if debonding of the node remains the dominant failure mode under shear loading. $\mathrm{Xu}$ et al. [24] fabricated composite corrugated panels using an auto-cutting process, with a graded core in the thickness direction. The developed analytical model and failure mechanism map were validated by experiments, and web topological grading was found to have a significant effect on the compressive failure mode but a negligible influence on the bending performance. Liu et al. [25-26] investigated the crashworthiness of the multi-cell CFRP tubes and the perforated square CFRP tubes. Their numerical model effectively replicated the progressive collapse mode of the CFRP tubes and good agreement was found between the experimental and numerical load-displacement curves.

In the marine industry, sandwich panels with a metallic prismatic core (of either a X-core or Y-core geometry) are often utilized in double hull design owing to their good energy absorption performance [27-28]. Hogstrom et al. [29] evaluated the energy absorption of several metallic sandwich structures and intrusion depth of the striking bow by a simulation method of the large-scale ship collisions. It was found the $\mathrm{X}$-core sandwich structure is a more crashworthy structure, however, the main challenge with the $\mathrm{X}$-core structure is the larger weight and cost. The metallic X-core sandwich structures are usually manufactured by the laser weld [30] and the laser weld properties could affect the global response of the X-core. The composite sandwich panels have the higher specific strength and stiffness and a better formability compared to the metallic structure, however, the brittle failure mechanism of the composite could induce catastrophic collapse of the sandwich structures. Hence, it is necessary to investigate the failure mechanism of composite sandwich panels to provide a useful guideline for the designers and engineers. The composite X-core sandwich panel may be regarded as an improvement over the double layer corrugated sandwich panel by taking advantage of its stout core ribs to improve buckling resistance. However, the method of fabrication and mechanical properties of composite X-core sandwich panels are not well studied in the literature. In this paper, a fabrication method was developed to manufacture CFRP X-core sandwich panel with different relative densities. The compressive properties and failure mechanisms of composite X-core sandwich panels are investigated by experimental, analytical and FE methods. The measured strength and stiffness, and the observed failure modes agree with theoretical results. Analytical formulas are derived to predict the compressive properties and the relation between the X-core geometric parameters and the failure modes. Finite element analysis (FEA) is employed to evaluate the effect of geometric imperfections and material damage on the response of the sandwich panel. Finally, the compressive properties of CFRP X-core sandwich panels were found to be competitive when compared to other sandwich structures with a cellular 
core architecture.

\section{Fabrication and experimental methods}

\subsection{Manufacturing process}

The unidirectional T700 Carbon fiber reinforced epoxy resin prepregs (provided by Shandong Jiangshan Fiber Technology Inc.) were used to fabricate the X-core sandwich panels, using a hot-press molding technique. The molds were specifically customized to manufacture sandwich panels with a X-core geometry of various different thicknesses. Figure 1 illustrates the fabrication procedure of the X-core sandwich panel. The different thicknesses of the X-core members, achieved through using composite prepregs with 4, 8, 12 and 16 layers, were controlled through the clearance between the adjacent unit molds. The thickness of each prepreg was $0.1 \mathrm{~mm}$, and the stacking sequences were $\left[0^{\circ} / 90^{\circ}\right]_{\mathrm{s}}$ for 4 layers, $\left[\left(0^{\circ} / 90^{\circ}\right)_{2}\right]_{\mathrm{s}}$ for 8 layers, $\left[\left(0^{\circ} / 90^{\circ}\right)_{3}\right]_{\mathrm{s}}$ for 12 layers and $\left[\left(0^{\circ} / 90^{\circ}\right)_{4}\right]_{\mathrm{s}}$ for 16 layers; hence, unit molds with different dimensions were manufactured to accommodate the thickness of the X-core member. Before assembly, the molds were sprayed with a release agent to facilitate material detachment post curing. The composite prepregs were cut into strips of appropriate size and placed into the mold such that the $0^{\circ}$-direction was aligned with the length of the mold. The prepared composite prepregs were assembled into the $\mathrm{X}$-core unit cell and the ends of the $\mathrm{X}$-core prepregs were inserted in the middle layer of the face sheets in order to increase the interfacial strength between the $\mathrm{X}$-core and face sheets (Fig. 1a). The assembled unit cell were assembled together to form an integer mold (Fig. 1b). Subsequently, the face sheets were placed on the top and bottom of the assembled X-core to create the sandwich structure (Fig. 1c). Both the face sheets and the X-core members had the same composite stacking sequence. The samples were cured for $1.5 \mathrm{~h}$ at $125^{\circ} \mathrm{C}$, while a uniform pressure was applied to enhance the CFRP quality (Fig. 1d). After curing, the molds were removed and the fabricated X-core sandwich panel was obtained (Fig. 1e).

The X-core sandwich panel fabricated through the hot-press method is presented in Fig. 2a. The inclination angle $\alpha$ of the flange was $60^{\circ}$, and the height $h$ of the X-core was $24.4 \mathrm{~mm}$. The average thickness $t_{\mathrm{c}}$ of X-core members was $0.32 \mathrm{~mm}, 0.67 \mathrm{~mm}, 1.06 \mathrm{~mm}$ and $1.48 \mathrm{~mm}$ for $4,8,12$ and 16 layers, respectively, as shown in Fig. $2 b$-e. The sandwich panels were constituted of a periodic unidirectional arrangement of four unit cells, as shown in Fig. 3. The unit cell section is characterized by a central X-core with flange length $l$ and web length $2 b$, and two top and bottom face sheets of length $2 L$, extruded for a depth $c$. The unit cell relative density is defined by the ratio of the $\mathrm{X}$-core sandwich volume to that of the limiting envelope, and it is given as

$$
\bar{\rho}=\frac{\left(2 l+b-3 t_{\mathrm{c}} / 4 \tan \alpha\right) t_{\mathrm{c}}}{L h}
$$

It can be noted that the relative density of the X-core unit cell increases non-linearly with member thickness $t_{\mathrm{c}}$. The dimensions and relative densities of the manufactured X-core sandwich panels are listed in Table 1.

\subsection{Material properties}

The mechanical properties of the unidirectional CFRP are listed in Table 2 - they were obtained through experiments performed on unidirectional CFRP panels fabricated from the same material. However, the mechanical properties of the laminated sheets may be affected (weakened) by the manufacturing process. Separately from the flat CFRP panel fabricated by the hot-press molding technology, the X-core members manufactured using a series of assembled prismatic unit molds also suffers from nonuniform pressure and temperature. The above factors led to a knock-down in the mechanical properties of the X-core members when compared to those measured from the unidirectional CFRP panel. Since the compressive and bending properties of laminates are the main factors affecting the compressive response of the X-core sandwich panel, laminates cut from the flanges of the sandwich panel were tested to obtain the reduced parameters. In this paper, the small sheet thickness of the constituent material made it difficult to measure the compressive strength and modulus by conducting standard ASTM D3410 tests [30]. The reduced thickness of the specimens could not reach the requirements to compensate for the beam-column effects caused by the bending moments induced by specimen and fixture tolerances [31]. Therefore, to diminish the error introduced by the small thickness, the average compressive modulus $E_{\mathrm{C}}$ and strength $\sigma_{s}$ obtained from the 16 layers laminate were assumed to be the mechanical properties of the constituent material. The bending stiffness $E_{B} I$ of the constituent material was measured according to ASTM D790 [32] on a 16 layers laminate. The average width 
and length of the specimens were $14 \mathrm{~mm}$ and $100 \mathrm{~mm}$, respectively, while the span $L$ to thickness $t$ ratio was 40/1. The specific geometric dimensions of CFRP specimens for the compressive and three-point bending experiments are given in Table 3. Compressive stress-strain curves and load-deflection curves obtained from the three-point bending tests for CFRP laminates are presented in Fig. 4a-b. The average experimental compressive and bending properties and their standard deviation are listed in Table 4 . The experimental results listed in Table 4 were used in the analytical and numerical models. However, the Poisson's ratio and shear modulus, for instance, have less influence on the predictive results; they were also difficult to accurately measure due to the dimensions of the X-core member. Hence, some of the unrevised parameters listed in Table 2 were also adopted.

\subsection{Compression tests}

The compressive mechanical properties of CFRP X-core sandwich panels were assessed through uniaxial experiments conducted in accordance with ASTM C365 [33]. Displacement was imposed on the specimen through the top platen at a loading rate of $0.5 \mathrm{~mm} / \mathrm{min}$, while the bottom platen was fixed, as shown in Fig. 5. During the tests, the force $F_{z}$ and the deformation $\delta_{z}$ along the loading direction were recorded by using a data acquisition software. The compressive engineering stress $\sigma_{z}$ on the X-core sandwich panel can be defined by

$$
\sigma_{z}=F_{z} /(8 \cdot L \cdot c)
$$

Thus, the compressive modulus $E_{z}$ of the $\mathrm{X}$-core sandwich panel can be calculated as

$$
E_{z}=\Delta \sigma_{z} /\left(\Delta \delta_{z} / h\right)
$$

where $\Delta \sigma_{z}$ and $\Delta \delta_{z}$ represent the increment of compressive stress and displacement in the linear elastic regime.

The evolution of the sample during compression and the failure morphologies were recorded by using a high-resolution camera. In order to ensure the repeatability of the results, three tests were carried out for each $\mathrm{X}$-core sandwich panel with a different flange thickness.

\section{Analytical modeling}

The analytical expressions that define the compressive stiffness and strength of the fabricated CFRP sandwich panel are presented in this section. These formulas, derived through the beam theory, allow evaluating the compressive properties of the X-core sandwich panel and predicting their failure modes. In the following, it is assumed that the flanges and webs are homogeneous, with the same thickness $t_{c}$, and characterized by the material compressive modulus $E_{C}$ and bending modulus $E_{B}$, as given in Table 3. Due to the periodic geometric configurations of the X-core sandwich panel, the simplified unit cell is shown in Fig. $6 a$. Since the deformation and internal forces are assumed to be the same along the $x$-axis direction, the following analysis considers only a 2D unit cell section. Under a compressive force $F$ acting along the $z$-axis, the vertical displacement of the unit cell top surface is $\delta_{z}$ (Fig. 6b). Because of symmetry, half of the X-core unit cell can be analyzed, as illustrated in Fig. 6c. The bottom flange is fixed, while the top flange is only allowed to slide vertically under the action of the compressive force. Each flange is subjected to an axial force $N_{1}$, a bending moment $M$ and shear force $S$, while the web has an axial force $N_{2}$. From the equilibrium and the compatible state of deformation, the internal forces and moment at any arbitrary cross-section of the $\mathrm{X}$-core unit cell are given as

$$
\begin{aligned}
& N_{1}=\frac{F}{2(\sin \alpha+J \cos \alpha)} \\
& N_{2}=\frac{(\cos \alpha-J \sin \alpha) \cdot F}{(\sin \alpha+J \cos \alpha)} \\
& S=\frac{J \cdot F}{2(\sin \alpha+J \cos \alpha)} \\
& M=\frac{J(l-2 \zeta) \cdot F}{4(\sin \alpha+J \cos \alpha)}
\end{aligned}
$$


where $\zeta$ is the distance from the local coordinate system based on the web (Fig. 6a) and $J$ is written as

$$
J=(l+2 b) /\left(\frac{E_{C} A l^{3}}{12 E_{B} I}+2 b\right) \tan \alpha
$$

where $A$ is the cross-section area, $I$ the moment of inertia about the $x$-axis, $l$ and $2 b$ are the length of the flange and web, respectively.

\subsection{Compressive stiffness}

The equivalent compressive properties of the $\mathrm{X}$-core sandwich panel can be evaluated by considering the unit cell to be homogeneous. Under this assumption, the strain energy of the equivalent unit cell due to the vertical compressive force $F$ is given as

$$
U_{\text {cell }}=\frac{1}{2} \int_{A} \frac{F^{2}}{E_{z} S_{\text {cell }}} d x d z
$$

where $E_{z}$ is the equivalent compressive modulus of the X-core sandwich panel in the z-direction and $S_{\text {cell }}$ is the surface area subjected to the compressive force $F$. Moreover, the strain energy stored in the flanges and web can be written in terms of internal forces and moment as

$$
U_{\varepsilon}=\frac{1}{2} \int_{A}\left(4 \cdot \frac{N_{1}^{2}}{E_{C} A}+4 \cdot \lambda \frac{S^{2}}{G A}+4 \cdot \frac{M^{2}}{E_{B} I}\right) d x d \zeta+\frac{1}{2} \int_{A}\left(\frac{N_{2}^{2}}{E_{C} A}\right) d x d y
$$

where $\lambda$ is the shear shape factor and $G$ is the shear modulus of the flange. Assuming that the shear strain energy is negligible, by imposing $U_{\varepsilon}=U_{\text {cell }}$ the equivalent compressive modulus can be calculated as

$$
E_{z}=\frac{(\sin \alpha+J \cos \alpha)^{2} l \sin \alpha / L}{\frac{l+2 b(\cos \alpha-J \sin \alpha)^{2}}{E_{C} A}+\frac{J^{2} l^{3}}{12 E_{B} I}}
$$

\subsection{Failure modes}

The compressive strength of the X-core sandwich panel can be obtained by analyzing the potential failure mechanisms, namely flange failure (FF), web failure (WF), flange shear failure (FS) and global buckling (GB).

\subsubsection{Flange failure}

The failure of the flange is attained when the maximum compressive stress within the flange $\sigma_{\text {flange }}$ reaches the compressive strength of the composite laminates $\sigma_{s}$, as given in Table 2. The maximum compressive stress in the flange can be determined from the internal forces of Eq. (4) as

$$
\sigma_{\text {flange }}=\frac{6 M}{t_{c}^{2}}+\frac{N_{1}}{t_{c}}=\frac{\left(3 J l+t_{c}\right) F}{2(\sin \alpha+J \cos \alpha) t_{c}^{2}}
$$

Therefore, the compressive stress on the X-core sandwich panel that induces flange failure, $\sigma_{f f}=F / 2 L$, becomes

\subsubsection{Web failure}

$$
\sigma_{f f}=\frac{(\sin \alpha+J \cos \alpha) t_{c}^{2} \sigma_{s}}{\left(3 J l+t_{c}\right) L}
$$

The failure of the web occurs when the axial compressive stress within the web $\sigma_{\text {web }}$ reaches the material compressive strength $\sigma_{s}$. The web compressive stress is obtained from the internal axial force as

$$
\sigma_{\text {weh }}=\frac{N_{2}}{t_{c}}=\frac{(\cos \alpha-J \sin \alpha) F}{(\sin \alpha+J \cos \alpha) t_{c}}
$$

while the web failure strength $\sigma_{w f}$ can written as 


$$
\sigma_{w f}=\frac{(\sin \alpha+J \cos \alpha) t_{c} \sigma_{z}}{(\cos \alpha-J \sin \alpha) B}
$$

\subsubsection{Flange shear failure}

The shear failure of the flange can be achieved when the shear stress equates to the shear strength of the constituent material. From Eq. (4), the average shear stress on the flange is written as

$$
\tau_{\text {flange }}=\frac{S}{t_{c}}=\frac{J \cdot F}{2(\sin \alpha+J \cos \alpha) t_{c}}
$$

and the shear failure strength $\sigma_{f s}$ of the flange is calculated as

$$
\sigma_{f s}=\frac{2(\sin \alpha+J \cos \alpha) t_{c} \tau_{s}}{J \cdot L}
$$

It should be noted that the shear stress is inversely proportional to the flange slenderness ratio. Hence, the flange shear stress is negligible for slender elements, and shear failure is unlikely to occur.

\subsubsection{Global buckling}

The global buckling analysis of the X-core is based on the theory of elastic buckling, where the flanges and web are treated as slender struts that buckle in the $y-z$ plane, as shown in Fig. 7a for the first buckling mode. The symmetric configuration of the X-core unit cell allows restricting the attention to the bottom part of the unit cell( Fig. 8b), where the buckling-induced internal forces are highlighted. These include the axial compressive force $N_{\mathrm{GA}}$ and shear force $Q_{\mathrm{GA}}$ in the flange $\mathrm{AG}$, and the bending moment $M_{G A}$ that develops at the upper end of the flange. Because of symmetry, the internal forces of the flange $\mathrm{BH}$ are equivalent to those of the flange $\mathrm{AG}$, hence only the flange $\mathrm{AG}$ is considered in the following. The relation between the axial force $N_{\mathrm{GA}}$ of the flange and the compressive force $F$ on the unit cell is obtained from Eq. (4a) as

$$
N_{\mathrm{GA}}=\frac{F}{2(\sin \alpha+J \cos \alpha)}
$$

The linearized differential equation that governs the deflection of the flange AG is

$$
\frac{\partial^{2} \omega}{\partial \zeta^{2}}+k^{2} \omega-\frac{Q_{\mathrm{GA}}(l-\zeta)-M_{\mathrm{GA}}}{E_{B} I}=0
$$

where $k^{2}=N_{\mathrm{GA}} / E_{B} I$. The general solution of Eq. (16) is

$$
\omega=A \sin k \zeta+B \cos k \zeta+\frac{Q_{\mathrm{GA}}(l-\zeta)-M_{\mathrm{GA}}}{N_{\mathrm{GA}}}
$$

where $A$ and $B$ are the coefficients determined by the following boundary conditions

$$
\begin{gathered}
\omega(0)=0,\left.\frac{\partial \omega}{\partial \zeta}\right|_{\zeta=0}=0 \\
\omega(l)=0,\left.\frac{\partial \omega}{\partial \zeta}\right|_{\zeta=l}=\frac{k^{2} M_{\mathrm{GA}} b}{N_{\mathrm{GA}}}
\end{gathered}
$$

The application of the boundary conditions (18) and (19) yields the following system of equations

$$
\left[\begin{array}{cc}
\sin k l-k l \cos k l & k \cos k l-k \\
\cos k l+k l \sin k l-1 & -k \sin k l-k^{2} b
\end{array}\right]\left[\begin{array}{c}
Q_{\mathrm{GA}} \\
M_{\mathrm{GA}}
\end{array}\right]=\left[\begin{array}{l}
0 \\
0
\end{array}\right]
$$

where a nontrivial solution exists only if the determinant of the matrix is equal to zero. The solution for the coefficient $k$ can be obtained numerically, so that the critical buckling force for the flange is calculated as

$$
N_{\mathrm{AG}}=k^{2} E_{B} I
$$

and the critical elastic buckling force of the X-core sandwich panel can be written from Eq. (15) as

$$
F_{c r}=2(\sin \alpha+J \cos \alpha) E_{B} I k^{2}
$$

Therefore, the critical global buckling strength of the X-core sandwich panel is given as 


\subsection{Failure mechanism map}

$$
\sigma_{c r}=\frac{(\sin \alpha+J \cos \alpha) E_{B} I k^{2}}{L}
$$

In this section, a failure mechanism map is obtained to predict the failure mode of the composite X-core sandwich panel and to illustrate the influence of the main design variables. The failure mechanism map can provide useful references to facilitate practical design and is widely used to demonstrate the effect of the geometric configurations on the failure modes of the sandwich structures with several competitive failure mechanisms $[5,6,17]$. Compared with 2D failure mechanism map, the 3D failure mechanism map is more intuitive and can present different failure mechanisms in one map. The analytical compressive strength of the X-core sandwich panel $\sigma_{z}$ is defined as the minimum strength of the failure modes analyzed before

$$
\sigma_{z}=\min \left\{\sigma_{f f}, \sigma_{w f}, \sigma_{f s}, \sigma_{c r}\right\}
$$

From Eqs. (10), (12), (14) and (23), it can be noted that the failure strength is depended on the mechanical properties of the constituent material and the unit cell topology, where the main independent geometrical parameters are the length $l$ and inclination angle $\alpha$ of the flanges, and the thickness $t_{c}$ of the X-core members. Since the web was designed to reduce the stress concentration that arises during the hot-press procedure, the length of the web is not considered as a design variable, but it is fixed to $3 \mathrm{~mm}$. By employing the compressive modulus $E_{\mathrm{C}}$, compressive strength $\sigma_{s}$ and bending stiffness $E_{B} I$ of the CFRP constituent material given in Table 3 , and the average shear strength $\tau_{s}=95 \mathrm{MPa}$ calculated from Table 2, the failure mechanism map is shown in Fig. 8.

In the failure map, the four main mechanisms, namely flange failure (FF), web failure (WF), flange shear failure (FS) and global buckling (GB), are reported as a function of the three independent design variables $l, \alpha$ and $t_{c}$. According to the failure map, X-core sandwich panels with low slenderness ratio $l / t_{c}$ and small flange inclination angle $\alpha$ tend to fail by flange shear when subjected to compression. In this case, due to the reduced resistance to the shear stress of the laminated CFRP sheets, the strength of the sandwich panel results limited. Hence, relatively large $l / t_{c}$ and $\alpha$ are recommended to avoid flange shear failure and to increase the strength of the composite X-core sandwich panel. On the other hand, high slenderness flanges induce failure by elastic instability, as seen from the global buckling region (GB) of Fig. 8. As the thickness $t_{c}$ increases, the fracture of the web occurs when the inclination angle $\alpha$ is small, whereas the flanges failure develops with large $\alpha$. To take advantage of the load-bearing capacity of the constituent material, the flange failure stress $\sigma_{\text {flange }}$ should be equal to the web failure stress $\sigma_{\text {web }}$. Therefore, the geometrical parameters that define the boundary between flange failure (FF) and web failure (WF) are sought. In particular, a flange inclination angle between $55^{\circ}$ and $65^{\circ}$ is recommended. For this reason, the sandwich panels fabricated in this work present an inclination angle $\alpha=60^{\circ}$ and a length $l$ of flange of $14.08 \mathrm{~mm}$. For the four sets of manufactured X-core sandwich panels with different thicknesses $t_{c}$, the predicted failure modes are marked with dots in Fig. 8. The X-core sandwich panels with relative density $\bar{\rho}=3.3 \%$ is predicted to fail via global buckling, while flange compressive failure occurs for relative densities $\bar{\rho}=6.7 \%, \bar{\rho}=10.3 \%$ and $\bar{\rho}=13.9 \%$.

\section{Finite element simulation}

According to the periodicity of the X-core sandwich panel, unit cells with different relative densities and stacking sequences were modeled by using the commercial finite element software ABAQUS 2016 (Dassault Systèmes), as shown in Fig. 9. The mechanical properties of the orthotropic CFRP material used in FE model are given in Tables 2 and 3. The $0^{\circ}$ and $90^{\circ}$ orientations of face sheets were aligned along the global $x$-axis and $y$-axis, respectively (Fig. 9a), while the $0^{\circ}$ and $90^{\circ}$ plies in the flanges and web followed the local $x$-axis and $y$-axis, respectively (Fig. 9b). A compressive force $F$ was applied on the top face sheet, while fixed boundary conditions were assigned to the bottom face sheet. Due to the symmetry of the model with respect to the $y$-direction, only half of the X-core depth was modeled, with symmetric boundary conditions inserted in the $x-z$ plane at half-depth, as shown in Fig. 9a. The X-core sandwich panel was discretized using linear 3D reduced integration solid elements (C3D8R), with a minimum element size of $0.5 \mathrm{~mm}$ determined by a mesh 
refinement analysis.

The analytical study showed that global buckling is the preferred failure mode for low slenderness X-core unit cells. Therefore, a nonlinear quasi-static analysis using the Riks pseudo-arc-length method was performed to obtain deformation modes and critical stresses for the X-core sandwich panel with low relative densities. Moreover, CFRP sandwich panels fabricated through hot-press molding can present geometric imperfections induced by manufacturing residual stresses or assembly errors. Since small stochastic imperfections could result in a remarkable reduction of the critical stress for a thin-wall structure under compression, an imperfection-sensitivity analysis was performed to investigate the effect of topological imperfections on the reduction of compressive properties. The geometric imperfections of the manufactured CFRP sandwich panels were difficult to quantify because of the small size of the X-core members. Therefore, a standard technique is to introduce in the numerical simulations an initial imperfect $\mathrm{X}$-core shape as a combination of its first three buckling modes [34-35]. In this work, six different amplitudes of buckling modes were considered, namely $0, l / 1000, l / 600, l / 400, l / 200$ and $l / 180$, where $l$ is the flange length. Each initial imperfection is obtained by the superposition of the first three buckling modes with various amplitudes, and introduced into the numerical model by revising the ABAQUS input file. For instance, one group of the amplitudes for the first three buckling modes were set as $l / 1000, l / 400$ and $l / 180$, respectively, while another group can be obtained by permutation of the six amplitudes considered.

On the other hand, geometric nonlinearities and imperfections have a negligible effect on the compressive behaviors of the X-core sandwich panels with non-slender flanges. In this case, a linear quasi-static analysis was adopted because it is computationally more efficient. In order to decide whether a non-linear or linear analysis was required for a particular unit cell relative density, the following procedure was employed. Firstly, elastic nonlinear analyses on imperfect unit cells were conducted to assess the effect of geometric imperfections on the compressive response and failure stress of the $\mathrm{X}$-core. If the unit cell response resulted insensitive to small imperfections, a linear analysis was carried out, while a nonlinear analysis was chosen for imperfection-sensitive unit cells. Once the imperfection-sensitivity study was completed and the type of analysis was decided, the Hashin failure criteria [36] was implemented in the simulation by means of a material user subroutine UMAT to predict material failure. Since there is a knock-down in the mechanical properties of the X-core member (due to fabrication), the revised compressive strength and modulus of the $\mathrm{X}$-core member listed in Table 4 were employed instead of the corresponding parameters listed in Table 2. The unrevised mechanical properties listed in Table 2 are assumed to have an insignificant influence on the results and are, therefore, employed in the numerical model without any reduction. The results of FE simulations are compared with analytical predictions and experimental measurements in the next section.

\section{Results and discussion}

\subsection{Experimental results}

Experimental engineering stress-strain curves of $\mathrm{X}$-core sandwich panels with different relative densities are shown in Figs. 10-11. Each plot is accompanied by four images (labeled as I to IV) of the sample at different compressive displacements, highlighting the failure modes. Fig. 10a presents the compressive behavior of the X-core sandwich panel with relative density $\bar{\rho}=3.3 \%$. It can be seen that after a linear-elastic region, buckling of some flanges occurs (II), followed by a limited plateau (III). Subsequently, the post-buckling regime is characterized by a gradual loss of the load-bearing capacity (IV) due to progressive deformation that leads to flange delamination and fracture. The stress-strain curves of the specimens with relative density $\bar{\rho}=6.7 \%$ are reported in Fig. 10b. They show a stiffer linear-elastic response (I, II) until the onset of fracture of the flanges (III), associated with a sharp drop of the stress. After the initial failure at the edges of the flanges, where the bending moment is higher, fracture and delamination on the X-core accumulated rapidly (IV), with the sample losing load-carrying capabilities. Similarly, Fig. $11 \mathrm{a}-\mathrm{b}$ conveys that brittle fracture of the flanges at $0.8 \%$ of engineering strain is the preferred failure mechanism for the X-core sandwich panels made of 12 and 16 layers of CFRP prepregs, corresponding to relative densities $\bar{\rho}=10.3 \%$ and $\bar{\rho}=13.9 \%$, respectively.

From the stress-strain curves, the measured peak stress and the slope of the linear-elastic region identify the compressive strength $\sigma_{z}$ and modulus $E_{z}$ of the X-core sandwich panels, respectively, as shown in Fig. $12 \mathrm{a}-\mathrm{b}$. The results indicate that the compressive properties increase as the thickness of flanges and web 
increases. In order to normalize the compressive features of the $\mathrm{X}$-core sandwich panel by their relative density $\bar{\rho}$, the non-dimensional strength $\psi_{z}$ and modulus $\sum_{z}$ are introduced as

$$
\begin{aligned}
& \psi_{z}=\sigma_{z} /\left(\sigma_{s} \bar{\rho}\right) \\
& \sum_{z}=E_{z} /\left(E_{C} \bar{\rho}\right)
\end{aligned}
$$

where $\sigma_{s}$ and $E_{C}$ are the measured compressive strength and modulus of the CFRP laminate given in Table 3. Figure 12a-b also shows the non-dimensional compressive properties of the manufactured sandwich panels as a function of the number of plies. It can be observed that the non-dimensional strength increases first and then decreases as the relative density increases, reaching a maximum for the panel with 12 plies (Fig. 12a). Differently, the non-dimensional stiffness remains almost constant for different relative densities, as shown in Fig. 12b.

\subsection{Finite element results}

The imperfection-sensitivity analysis described in Sect. 4 was performed on the X-core unit cells with relative densities $\bar{\rho}=3.3 \%, \bar{\rho}=6.7 \%$ and $\bar{\rho}=10.3 \%$, by introducing different combinations of the first three buckling modes presented in Fig. 13. The numerical compressive responses of the X-core unit cells with an initial imperfect shape as the first buckling mode are reported in Fig. 14a-b. Figure 14a shows that the analytically-derived buckling stress of the X-core unit cell with $\bar{\rho}=3.3 \%$ underestimates by $15.1 \%$ the strength obtained from the numerical prediction of a perfect unit cell. Furthermore, it conveys that the global imperfections significantly affect the buckling stress, with a reduction of more than $34.0 \%$ when compared with the perfect unit cell. Figure $14 \mathrm{~b}$ reports the results for the X-core sandwich panels with $\bar{\rho}=6.7 \%$ and $\bar{\rho}=10.3 \%$, where it can be observed that the buckling stress of the perfect unit cell is larger than the strength caused by flange failure, which is the preferred mechanism as predicted from the analytical investigation. However, when imperfections are introduced, the critical strength for X-core unit cell with $\bar{\rho}=6.7 \%$ falls below the analytical value, suggesting that the presence of imperfections can lead to a change in failure mode. Differently, unit cell with $\bar{\rho}=10.3 \%$ is not significantly affected by imperfections, and the buckling strength remains considerably larger than the flange failure stress. Therefore, a nonlinear analysis with geometric imperfections is recommended for X-core sandwich panels with relative densities $\bar{\rho}=3.3 \%$ and $\bar{\rho}=6.7 \%$, while a linear analysis can be performed for lower slenderness unit cells.

When material damage was introduced in the finite element analysis through the Hashin criterion, it was possible to obtain the X-core panel response until failure. According to the numerical nonlinear analyses, the shapes of imperfections have a significant influence on the failure regions, while the amplitudes affect the failure stress. Symmetric buckling modes and failure regions were found when the first two symmetric buckling modes were introduced as geometric imperfections, whereas antisymmetric failure developed when the antisymmetric third buckling mode was introduced as initial imperfect shape. The combination of initial imperfections can induce an asymmetrical buckling mode and a local failure in the middle of the flange, in agreement with the results of experiments for X-core sandwich panels with relative densities $\bar{\rho}=3.3 \%$ and $\bar{\rho}=6.7 \%$, Fig. 10. Therefore, a combination of the first three buckling modes was introduced as the initial geometric imperfection and different amplitudes of each buckling modes were employed to investigate the effects on the numerical results.

Figure 15 reports the comparison between experimental and numerical stress-strain curves of the four unit cells with different relative densities. The insets in each plot show the distribution of the damage parameter, where the blue regions represent undamaged material, while material failure is indicated by a red area. Figure $15 \mathrm{a}-\mathrm{b}$ refers to unit cells with relative densities $\bar{\rho}=3.3 \%$ and $\bar{\rho}=6.7 \%$, where both the nonlinear responses of the perfect and geometrically imperfect unit cells are shown. The representative initial geometric imperfections introduced in FE(imp) models shown in Fig. 15a-b for X-core sandwich panels with $\bar{\rho}=3.3 \%$ and $\bar{\rho}=6.7 \%$ are given in Fig. 16 . For the geometrically imperfect unit cell with relative densities $\bar{\rho}=3.3 \%$, the amplitude of each buckling modes introduced as imperfection was $l / 600$. It can be seen that both the perfect and imperfect unit cell with $\bar{\rho}=3.3 \%$ undergo global buckling (GB) before progressive distortion induces delamination (DL) of the flanges. However, the imperfect geometry can capture the entire experimental response well, while the perfect unit cell overpredicts the buckling strength. Figure $15 \mathrm{~b}$ shows 
the nonlinear response of the imperfect unit cell with 8 layers $(\bar{\rho}=6.7 \%)$, obtained by introducing an initial imperfection with an amplitude of $l / 1000$ for the first two buckling modes and of $l / 180$ for the third buckling mode. Similarly to the previous case, the numerical prediction of the imperfect unit cell has a better agreement with experiments than the perfect geometry. This behavior is explained by the higher sensitivity to imperfections of slender architectures, which reduces the ultimate strength. The failure mechanism from finite element analysis is flange fracture, as analytically predicted and experimentally observed. Fig. 15c-d reports only the results from the linear analysis because of the negligible imperfection-sensitivity of non-slender panels with relative densities $\bar{\rho}=10.3 \%$ and $\bar{\rho}=13.9 \%$. The numerical compressive response and failure mechanisms of X-core sandwich panel with these two relative densities are similar. For both geometries, the engineering stress-strain curve is linear elastic until the peak stress, when failure occurs at the upper and bottom ends of the flanges, as detected from experiments. The rapid propagation of damage causes the $\mathrm{X}$-core sandwich panels to rapidly lose the load-bearing capacity.

To investigate the effect of geometric configuration on the failure mechanism, the numerical models of the $\mathrm{X}$-core sandwich panels with different length $l$ and inclination angle $\alpha$ of the flanges, and the thickness $t_{c}$ of the X-core members are applied. The numerical cases are named by their geometric configurations as shown Fig. 17a-b, for example, n4-0.32-60-14 means a 4 layers X-core with a thickness $t_{c}$ of $0.32 \mathrm{~mm}$, an incline angle $\alpha$ of $60^{\circ}$ and a length $l$ of $14 \mathrm{~mm}$. The numerical stress-strain curves are presented in Fig. $17 \mathrm{a}-\mathrm{b}$ and the numerical failure modes of the X-core sandwich panels with different geometric configurations are shown in Fig. 17c. It can be found the flange fracture is the most common cause of failure, whereas the web fracture occurs for the X-core with a small inclination angle. The global buckling is the main failure mode for a X-core with slender members, but for a X-core with extremely stout members, the appearance of a shear delamination failure could be observed. The numerical results are plotted in Fig. 18, the 2D failure mechanism maps, to compare with the analytical predictions. Good agreement is observed between the numerical and analytical predictions for the failure mechanisms, while there are mixed failure modes for the cases n8-0.67-45-5 and n16-2.72-45-28 as marked in Fig. 18b. It is noted that the onset failure mode of the numerical models are in accordance with the analytical results, however, the X-cores with the stout members are prone to failure with a progressive failure process whereby mixed failure modes could occur until the ultimate failure.

\subsection{Comparison of analytical predictions with experimental measurements and FE simulations}

The comparison between analytical results, numerical simulations and experimental measurements are listed in Table 5 and presented in Figure 19, where the compressive strength $\sigma_{z}$ (Fig. 19a) and the compressive stiffness $E_{z}$ (Fig. 19b) are reported as a function of the X-core sandwich panel relative density $\bar{\rho}$ when the flange inclination is $\alpha=60^{\circ}$ and the flange length $l$ is fixed to $14.08 \mathrm{~mm}$.

From Fig. $19 \mathrm{a}$, it can be noted that the analytical study predicts a critical relative density $\bar{\rho}_{\mathrm{c}}=5.8 \%$ that distinguishes the two different mechanisms of global buckling $\left(\bar{\rho}_{\mathrm{c}}<5.8 \%\right)$ and flange failure $\left(\bar{\rho}_{\mathrm{c}}>\right.$ $5.8 \%$ ). Therefore, the analytical failure mode of the X-core sandwich panel with $\bar{\rho}=3.3 \%$ is global buckling, while the panels with $\bar{\rho}=6.7 \%, \bar{\rho}=10.3 \%$ and $\bar{\rho}=13.9 \%$ experience flange failure. These predictions were confirmed from both numerical and experimental results, as observed in Figs. 10, 11 and 15. The analytical strength overestimates the experimental ultimate stress, mainly because the analytical model does not include manufacturing-induced geometric imperfections for slender panels, and it does not capture the stress concentrations at the flange ends that lead to failure of non-slender geometries. The strength predicted from the finite element analyses on perfect X-core panels has a very good agreement with the analytical prediction for slender structures $(\bar{\rho}=3.3 \%$ and $\bar{\rho}=6.7 \%)$, while it deviates when the relative density increases, as a result of the stress concentrations in the nodes not modeled in the analytical formulation. Therefore, the numerical strength for panels with relative densities of $10.3 \%$ and $13.9 \%$ results more accurate in the prediction of the experimental values. Although the finite element ultimate stress of perfect X-core unit cells with relative densities of $3.3 \%$ and $6.7 \%$ is not in good agreement with the measured values, initial geometric imperfections are found to be the cause of premature failure of the sample, and the maximum strength of imperfect $\mathrm{X}$-core panels closely match the experimental data. 
The stiffness $E_{z}$ of the X-core sandwich panel is reported in Fig. 19b, where the analytically-derived modulus is observed to increase linearly with the relative density $\bar{\rho}$. As for the stiffness prediction, the analytical modulus reasonably overestimates the experimental one, while the numerical predictions report more accurate results compared with measured data, with a maximum relative error of $16.2 \%$. The discrepancy between predicted and measured values is mainly attributed to the presence of defects and imperfections from the fabrication, which decreases the stiffness of the panels.

\subsection{Comparison with other cellular materials}

The compressive strength and equivalent modulus of the manufactured CFRP X-core sandwich panels are compared with other structural cellular materials in Fig. 20. In the modified Ashby material selection maps, the compressive strength and modulus are plotted as a function of the material density, defined as $\rho=\bar{\rho} \cdot \rho_{0}$, where $\bar{\rho}$ is the relative density of the cellular material and $\rho_{0}$ is the density of the constituent material. The CFRP density $\rho_{0}$ for the fabricated X-core sandwich panel is $1500 \mathrm{~kg} / \mathrm{m}^{3}$. The compressive mechanical properties of CFRP pyramidal lattice [10], Al honeycomb [38], CFRP corrugated panel [39], CFRP 3D corrugated panel [24], GFRP corrugated panel [39], CFRP octet-truss [40], Ti-6Al-4V octet-truss [41] are also given in Fig. 17 for comparison. It can be noted that the compressive strength and modulus of the CFRP X-core sandwich panel result superior to any foams, and comparable to those of CFRP corrugated panel and CFRP octet-truss structure. High-slenderness X-core panels do not significantly improve the strength of existing cellular materials, because of buckling that considerably reduces the ultimate stress. However, the compressive strength of CFRP X-core with a density above $100 \mathrm{~kg} / \mathrm{m}^{3}$ is competitive among sandwich structures with lattice truss cores and corrugated cores. Furthermore, the compressive modulus of the fabricated CFRP X-core sandwich panels outperforms the majority of high-stiffness cellular materials, except Al honeycomb. Therefore, CFRP X-core sandwich panel represents a valid alternative to metallic and composite sandwich structures for marine and aerospace applications.

\section{Conclusions}

The compressive mechanical properties of CFRP X-core sandwich panel were analytically, numerically and experimentally investigated. Sandwich panels with different relative densities were manufactured with a hot-press molding technique and tested under uniaxial compression. Global buckling of the X-core was observed for sandwich panel with a relative density $\bar{\rho}=3.3 \%$, while flange failure was found for panels with higher relative densities, namely $\bar{\rho}=6.7 \%, \bar{\rho}=10.3 \%$ and $\bar{\rho}=13.9 \%$. The specific stiffness increased with an increase of the relative density, while the specific strength showed a maximum for the X-core panel with $\bar{\rho}=10.3 \%$. Analytical models were developed to characterize the compressive response of the X-core sandwich panel and to establish a failure mechanism map for the prediction of the failure modes as a function of the X-core geometric parameters. Furthermore, a critical relative density was found, below which buckling is the preferred mechanism, while flange failure occurs at higher relative densities. Finite element analyses were performed to further investigate the compressive properties when initial geometric imperfections and progressive damage of the CFRP material are introduced. Although the analytical results were in fair agreement with experimental measures, finite element simulations guaranteed a very good prediction of the compressive properties, because they were able to capture the significant reduction of strength associated with initial imperfections in slender panels, and failure due to stress concentrations in non-slender X-cores. Finally, it was shown that the fabricated CFRP X-core sandwich panels attained compressive properties higher or comparable to other cellular materials, with potential applications in lightweight structures.

\section{Acknowledgement}

The present work is supported by National Science Foundation of China under Grant Nos. 11402094 and 11802100, and the Open-ended fund of Science and Technology on Advanced Composites in Special Environments Laboratory under Grant No.61409220203. F.B. acknowledges the support from The Royal Society (RGS-R1-191459).

\section{References}

[1] J. Xu, Y.B. Wu, L.B. Wang, J.N. Li, Y.W. Yang, Y.L. Tian, Z.Z. Gong, P.L. Zhang, S. Nutt, S. Yin, Compressive properties of hollow lattice truss reinforced honeycombs (Honeytubes) by additive 
manufacturing: Patterning and tube alignment effects, Mater. Design. 156 (2018) 446-457. http://10.1016/j.matdes.2018.07.019.

[2] J. Xiong, L. Feng, R. Ghosh, L.Z. Wu, L. Ma, A. Vaziri, Fabrication and mechanical behavior of carbon fiber composite sandwich cylindrical shells with corrugated cores, Compos. Struct. 156 (2016) 307-319. http://10.1016/j.compstruct.2015.10.009.

[3] S. Jiang, F.F. Sun, H.L. Fan, D.N. Fang, Fabrication and testing of composite orthogrid sandwich cylinder, Compos. Sci. Technol. 142 (2017) 171-179. http://10.1016/j.compscitech.2017.02.009.

[4] H.L. Fan, D.N. Fang, L.M. Chen, Z. Dai, W. Yang, Manufacturing and testing of a CFRC sandwich cylinder with Kagome cores, Compos. Sci. Technol. 69(15-16) (2009) 2695-2700. http://10.1016/j.compscitech.2009.08.012.

[5] J. Xiong, R. Ghosh, L. Ma, A. Vaziri, Y.L. Wang, L.Z. Wu, Sandwich-walled cylindrical shells with lightweight metallic lattice truss cores and carbon fiber-reinforced composite face sheets, Compos. Part A. 56(1) (2014) 226-238. http://10.1016/j.compositesa.2013.10.008.

[6] Y.T. Du, C.P. Song, J. Xiong, L.Z. Wu, Fabrication and mechanical behaviors of carbon fiber reinforced composite foldcore based on curved-crease origami, Compos. Sci. Technol. 174 (2019) 94-105. http://10.1016/j.compscitech.2019.02.019.

[7] J.L. Liu, C. Li, Deng S.H., J.Y. Liu, W. Huang, The edgewise compressive behavior and failure mechanism of the composite Y-frame core sandwich column, Polym. Test. 81 (2020) 106188. http://10.1016/j.polymertesting.2019.106188.

[8] J.L. Liu, J.Y. Liu, J. Mei, W. Huang, Investigation on manufacturing and mechanical behavior of all-composite sandwich structure with Y-shaped cores, Compos. Sci. Technol. 159 (2018) 87-102. http://10.1016/j.compscitech.2018.08.005.

[9] J. Xiong, L. Ma, A. Vaziri, J. Yang, L. Wu, Mechanical behavior of carbon fiber composite lattice core sandwich panels fabricated by laser cutting, Acta. Mater. 60(13-14) (2012) 5322-5334. http://10.1016/j.actamat.2012.06.004.

[10] K. Finnegan, G. Kooistra, H.N.G. Wadley, V.S. Deshpande, The compressive response of carbon fiber composite pyramidal truss sandwich cores, Int. J. Mater. Res. 98(12) (2007) 1264-1272. $10.3139 / 146.101594$

[11] T. George, V.S. Deshpande, H.N.G. Wadley, Mechanical response of carbon fiber composite sandwich panels with pyramidal truss cores, Compos. Part A. 47 (2013) 31-40. http://10.1016/j.compositesa. 2012.11.011.

[12] W. Huang, Z.H. Fan, W. Zhang, J. Y. Liu, W. Zhou, Impulsive response of composite sandwich structure with tetrahedral truss core, Compos. Sci. Technol. 176 (2019) 17-28. http://10.1016/j.compscitech.2019.03.020.

[13] W. Huang, H.J. Xu, Z.H. Fan, W.M. Jiang, J.Y. Liu, Dynamic failure of ceramic particle reinforced foam-filled composite lattice core. Compos. Sci. Technol. $193 \quad$ (2020) 108143. http://10.1016/j.compscitech.2020.108143.

[14] V.S. Deshpande, N.A. Fleck, M.F. Ashby, Effective properties of the octet-truss lattice material, J. Mech. Phys. Solids. 49(8) (2011) 1747-1769. http://10.1016/S0022-5096(01)00010-2.

[15] X.Y. Wu, D.F. Li, J. Xiong, Fabrication and mechanical behaviors of an all-composite sandwich structure with a hexagon honeycomb core based on the tailor-folding approach, Compos. Sci. Technol. 184 (2019) 107878. http://10.1016/j.compscitech.2019.107878.

[16] G.Q. Li, V.D. Muthyala, Impact characterization of sandwich structures with an integrated orthogrid stiffened syntactic foam core, Compos. Sci. Technol. 68(9) (2008) 2078-2084. http://10.1016/j.compscitech.2008.03.014.

[17] J. Xiong, L. Ma, A. Stocchi, J.S. Yang, L.Z. Wu, S.D. Pan, Bending response of carbon fiber composite sandwich beams with three dimensional honeycomb cores, Compos. Struct. 108 (2014) 234-242. http://10.1016/j.compstruct.2013.09.035.

[18] S. Jiang, F.F. Sun, X. Zhang, H.L. Fan, Interlocking orthogrid: an efficient way to construct lightweight lattice-core sandwich composite structure, Compos. Struct. 176 (2017) 55-71. http://10.1016/j.compstruct.2017.05.029.

[19] J. Huang, Q.H. Zhang, F. Scarpa, Y. Liu, J.S. Leng, In-plane elasticity of a novel auxetic honeycomb design, Compos. Part B. 110 (2017) 72-82. http://10.1016/j.compositesb.2016.11.011. 
[20] X.T. Wang, B. Wang, Z.H. Wen, L. Ma, Fabrication and mechanical properties of CFRP composite three-dimensional double-arrow-head auxetic structures. Compos. Sci. Technol. 164 (2018) 92-102. http://10.1016/j.compscitech.2018.05.014.

[21] Y.T. Du, C.P. Song, J. Xiong, L.Z. Wu, Fabrication and mechanical behaviors of carbon fiber reinforced composite foldcore based on curved-crease origami, Compos. Sci. Technol. 174 (2019) 94-105. http://10.1016/j.compscitech.2019.02.019.

[22] S. Kazemahvazi, D. Tanner, D. Zenkert, Corrugated all-composite sandwich structures. Part 2: Failure mechanisms and experimental programme, Compos. Sci. Technol. 69(7-8) (2009) 920-925. http://10.1016/j.compscitech.2008.11.035.

[23] Y. Hu, W.X. Li, X.Y. An, H.L. Fan, Fabrication and mechanical behaviors of corrugated lattice truss composite sandwich panels. Compos. Sci. Technol. $125 \quad$ (2016) 114-122. http://10.1016/j.compscitech.2016.02.003.

[24] G.D. Xu, Z.H. Wang, T. Zeng, S. Cheng, D.N. Fang, Mechanical response of carbon/epoxy composite sandwich structures with three-dimensional corrugated cores, Compos. Sci. Technol. 156 (2018) 296-304. http://10.1016/j.compscitech.2018.01.015.

[25] Q. Liu, J. Fu, Y.T. Ma, Y.Q. Zhang, Q. Li, Crushing responses and energy absorption behaviors of multi-cell CFRP tubes, Thin. Wall. Struct. 155 (2020) 106930. http://10.1016/j.tws.2020.106930.

[26] Q. Liu, K. Liufu, Z. Cui, J. Li, J. Fang, Q. Li, Multiobjective optimization of perforated square CFRP tubes for crashworthiness, Thin. Wall. Struct. 149 (2020) 106628. http://10.1016/j.tws.2020.106628.

[27] V. Rubino, V.S. Deshpande, N.A. Fleck, The three-point bending of Y-frame and corrugated core sandwich beams, Int. J. Mech. Sci. 52(3) (2010) 485-494. http://10.1016/j.ijmecsci.2009.11.009.

[28] S. Ehlers, K. Tabri, J. Romanoff, P. Varsta, Numerical and experimental investigation on the collision resistance of the X-core structure, Ships Offshore Struc. 7(1) (2012) 21-29. http://10.1080/17445302.2010.532603.

[29] P. Hogstroem, J.W. Ringsberg. Assessment of the crashworthiness of a selection of innovative ship structures[J]. Ocean Eng. 59 (2013) 58-72. http://10.1016/j.oceaneng.2012.12.024.

[30] M. Wolf 2003. Full scale collision experiment, X-type Sandwich side hull. EU Sandwich project report Deliverable TRD448, EU Sandwich project, p. 21.

[31] ASTM D3410, Standard Test Method for Compressive Properties of Polymer Matrix Composite Materials with Unsupported Gage Section by Shear Loading, ASTM Int, West Conshohocken (PA), 2016.

[32] B.P. Russell, V.S. Deshpande, H.N.G.Wadley, Quasistatic Deformation and failure modes of composite square honeycombs, J. Mech. Mater. and Struct. 3(7) (2008) 1315-1340. http://10.2140/jomms. 2008.3.1315.

[33] ASTM D790, Standard Test Methods for Flexural Properties of Unreinforced and Reinforced Plastics and Electrical Insulating Materials, ASTM Int, West Conshohocken (PA), 2016.

[34] ASTM C365, Standard Test Method for Flatwise Compressive Properties of Sandwich Cores, ASTM Int, West Conshohocken (PA), 2016.

[35] EN 1993-1-6 Eurocde 3: Design of Steel Structures, Part 1.6 Strength and Stability of Shell Structures, CEN, Brussels (2007).

[36] C. Dou, Y.L. Pi, W. Gao, Shear resistance and post-buckling behavior of corrugated panels in steel plate shear walls, Thin. Wall. Struct. 131 (2018) 816-826. http://10.1016/j.tws.2018.07.039.

[37] Z. Hashin, Failure criteria for unidirectional fiber composites, J. Appl. Mech. 47 (1980) 329-334.

[38] PAMG-XR1 5056 Aluminium Honeycomb, MI 49464-0170.

[39] M.R.M. Rejab, W.J. Cantwell, The mechanical behaviour of corrugated-core sandwich panels, Compos. Part B. 47 (2013) 267-277. http://10.1016/j.compositesb.2012.10.031.

[40] L. Dong, H. Wadley, Mechanical properties of carbon fiber composite octet-truss lattice structures, Compos. Sci. Technol. 119 (2015) 26-33. http://10.1016/j.compscitech.2015.09.022.

[41] Q.Z. Li, E.Y. Chen, D.R. Bice, D.C. Dunand, Mechanical Properties of Cast Ti-6Al-4V Lattice Block Structures, Metall. Mater. Trans. A. 39(2) (2008) 441-449. http://10.1007/s11661-007-9440-y. 
Table 1. Dimensions of the X-core sandwich panels with different relative densities.

\begin{tabular}{ccccccc}
\hline $\begin{array}{c}\text { Number of } \\
\text { layers }\end{array}$ & $\begin{array}{c}\text { Relative } \\
\text { density } \bar{\rho}\end{array}$ & $\begin{array}{c}\text { Thickness of } \\
\text { flange } t_{\text {c }}\end{array}$ & $\begin{array}{c}\text { Height of } \\
\text { X-core } h\end{array}$ & $\begin{array}{c}\text { Width of unit } \\
\text { cell } 2 L\end{array}$ & $\begin{array}{c}\text { Depth of unit } \\
\text { cell } c\end{array}$ & $\begin{array}{c}\text { No. of } \\
\text { unit cells }\end{array}$ \\
\hline 4 & $3.3 \%$ & $0.32 \pm 0.02 \mathrm{~mm}$ & $24.4 \mathrm{~mm}$ & $23.6 \pm 0.05 \mathrm{~mm}$ & $102.0 \pm 1.0 \mathrm{~mm}$ & 4 \\
8 & $6.7 \%$ & $0.67 \pm 0.02 \mathrm{~mm}$ & $24.4 \mathrm{~mm}$ & $24.4 \pm 0.05 \mathrm{~mm}$ & $102.0 \pm 1.0 \mathrm{~mm}$ & 4 \\
12 & $10.3 \%$ & $1.06 \pm 0.02 \mathrm{~mm}$ & $24.4 \mathrm{~mm}$ & $24.9 \pm 0.05 \mathrm{~mm}$ & $102.0 \pm 1.0 \mathrm{~mm}$ & 4 \\
16 & $13.9 \%$ & $1.48 \pm 0.02 \mathrm{~mm}$ & $24.4 \mathrm{~mm}$ & $25.6 \pm 0.05 \mathrm{~mm}$ & $102.0 \pm 1.0 \mathrm{~mm}$ & 4 \\
\hline
\end{tabular}

Table 2. Mechanical properties of CFRP.

\begin{tabular}{lc}
\hline \multicolumn{1}{c}{ Properties } & Value \\
\hline Longitudinal modulus (GPa) & $E_{11}=100.0$ \\
Transverse modulus (GPa) & $E_{22}=8.0$ \\
Out-of-plane modulus (GPa) & $E_{33}=8.0$ \\
Shear modulus (GPa) & $G_{12}=G_{13}=4.0 ; G_{23}=3.0$ \\
Poisson's ratio & $v_{12}=v_{13}=0.21 ; v_{23}=0.3$ \\
Shear strength (MPa) & $S_{12}=S_{13}=104 ; S_{23}=86$ \\
Longitudinal tensile strength (GPa) & $X_{T}=2.1$ \\
Longitudinal compressive strength (GPa) & $X_{C}=0.7$ \\
Transverse tensile strength (MPa) & $Y_{T}=42$ \\
Transverse compressive strength (MPa) & $Y_{C}=160.0$ \\
Out-of-plane tensile strength (MPa) & $Z_{T}=42$ \\
Out-of-plane compressive strength (MPa) & $Z_{C}=160.0$ \\
\hline
\end{tabular}


Table 3. The geometric dimensions of CFRP specimens used for the compression and three-point bending tests.

\begin{tabular}{cccccccc}
\hline $\begin{array}{c}\text { Compressive } \\
\text { specimens }\end{array}$ & $\begin{array}{c}\text { Guage length } \\
(\mathrm{mm})\end{array}$ & $\begin{array}{c}\text { Width } \\
(\mathrm{mm})\end{array}$ & $\begin{array}{c}\text { Thickness } \\
(\mathrm{mm})\end{array}$ & $\begin{array}{c}\text { Bending } \\
\text { specimens }\end{array}$ & $\begin{array}{c}\text { Thickness } \\
(\mathrm{mm})\end{array}$ & Width (mm) & Span (mm) \\
\hline C-1 & 14.57 & 12.69 & 1.42 & B-1 & 1.43 & 14.41 & 64.0 \\
C-2 & 13.27 & 14.41 & 1.39 & B-2 & 1.52 & 13.05 & 64.0 \\
C-3 & 15.73 & 12.27 & 1.45 & B-3 & 1.49 & 12.61 & 64.0 \\
& & & & B-4 & 1.51 & 13.37 & 64.0 \\
& & & & B-5 & 1.44 & 12.47 & 64.0 \\
\hline
\end{tabular}

Table 4. Mechanical properties of the fabricated composite laminate for the X-core sandwich panel.

\begin{tabular}{ccccc}
\hline $\begin{array}{c}\text { Number } \\
\text { of layers }\end{array}$ & $\begin{array}{c}\text { Stacking } \\
\text { sequence }\end{array}$ & $\begin{array}{c}\text { Compressive modulus } \\
E_{\mathrm{C}}(\mathrm{GPa})\end{array}$ & $\begin{array}{c}\text { Compressive strength } \\
\sigma_{\mathrm{s}}(\mathrm{MPa})\end{array}$ & $\begin{array}{c}\text { Bending stiffness } \\
E_{\mathrm{B}} I(\mathrm{~N} \cdot \mathrm{m})\end{array}$ \\
\hline 16 & {$\left[\left(0^{\circ} / 90^{\circ}\right)_{4}\right]_{\mathrm{s}}$} & $48.4 \pm 4.5$ & $306.4 \pm 9.1$ & $15.1 \pm 1.3$ \\
\hline
\end{tabular}

Table 5. Experimental, analytical and numerical strength, modulus and failure mode of the X-core sandwich panels.

\begin{tabular}{|c|c|c|c|c|c|c|c|c|c|c|}
\hline \multirow[t]{2}{*}{$\begin{array}{c}\text { R.D. } \\
\bar{\rho}(\%)\end{array}$} & \multirow[t]{2}{*}{$\begin{array}{l}\text { Thickness } \\
t_{c} \quad(\mathrm{~mm})\end{array}$} & \multicolumn{3}{|c|}{ Experiment } & \multicolumn{3}{|c|}{ Analytical } & \multicolumn{3}{|c|}{ Numerical } \\
\hline & & $\begin{array}{l}\text { Strength } \\
(\mathrm{MPa})\end{array}$ & $\begin{array}{l}\text { Modulus } \\
(\mathrm{MPa})\end{array}$ & F.M. & $\begin{array}{l}\text { Strength } \\
\text { (MPa) }\end{array}$ & $\begin{array}{c}\text { Modulus } \\
(\mathrm{MPa})\end{array}$ & F.M. & $\begin{array}{c}\text { Strength } \\
\text { (MPa) }\end{array}$ & $\begin{array}{c}\text { Modulus } \\
(\mathrm{MPa})\end{array}$ & F.M. \\
\hline 3.3 & 0.32 & $1.45 \pm 0.13$ & $634.88 \pm 28.43$ & GB & 2.27 & 805.39 & GB & 1.65 & 731.21 & GB \\
\hline 6.7 & 0.67 & $7.22 \pm 0.24$ & $1287.11 \pm 62.50$ & $\mathrm{FF}$ & 12.94 & 1640.26 & $\mathrm{FF}$ & 7.87 & 1447.63 & $\mathrm{FF}$ \\
\hline 10.3 & 1.06 & $15.41 \pm 0.91$ & $1971.37 \pm 41.85$ & $\mathrm{FF}$ & 18.89 & 2520.12 & FF & 17.29 & 2298.48 & $\mathrm{FF}$ \\
\hline 13.9 & 1.48 & $18.93 \pm 0.55$ & $2729.70 \pm 86.22$ & $\mathrm{FF}$ & 24.29 & 3415.50 & $\mathrm{FF}$ & 20.12 & 3081.35 & $\mathrm{FF}$ \\
\hline
\end{tabular}

(R.D. refers to relative density; F.M. refers to failure mode) 


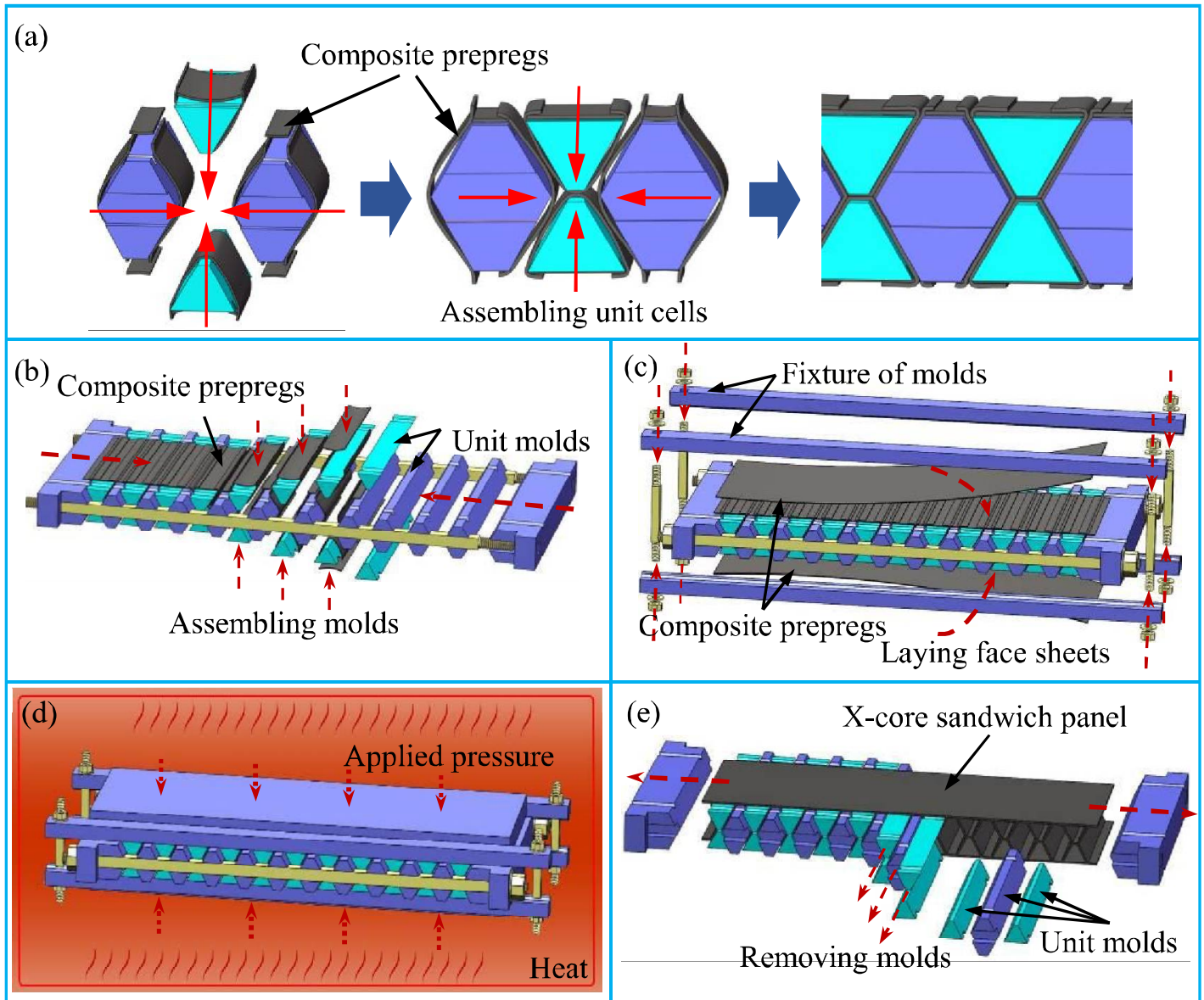

Fig. 1. Schematic illustration of the fabrication process of the X-core sandwich panel: (a) the prepared composite prepregs were assembled into the X-core unit cell; (b) the prepared composite prepregs were placed in the corresponding position of the mold; (c) the top and bottom face sheets were added on the assembled X-core; (d) the mold assembly was cured at $125^{\circ} \mathrm{C}$ for 1.5 hours; (e) the fabricated $\mathrm{X}$-core sandwich panel was obtained by removing the molds. 


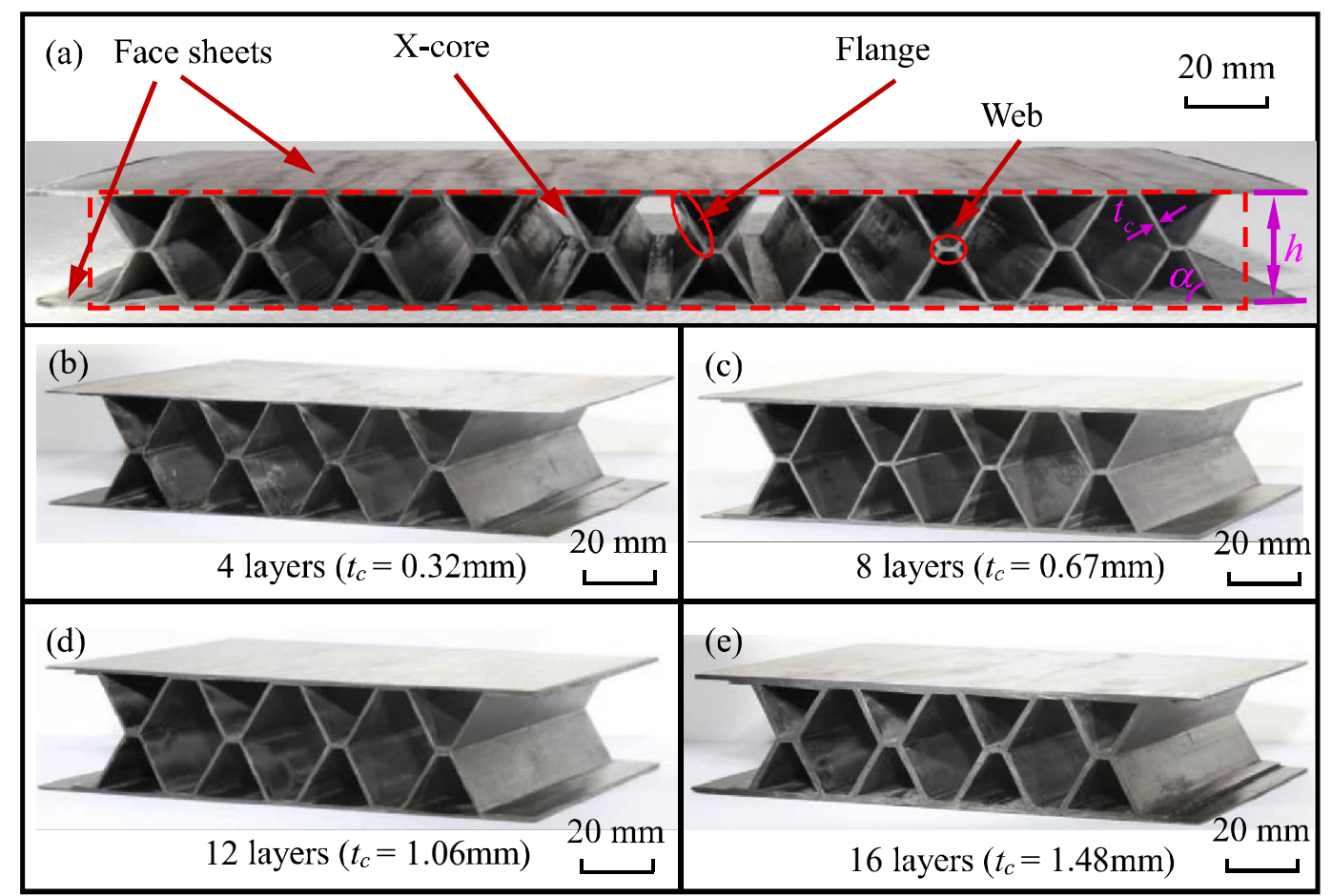

Fig. 2. (a) A representative composite X-core sandwich panel and the manufactured panels made of 4 (b), 8 (c), 12 (d), and 16 (e) prepregs layers.

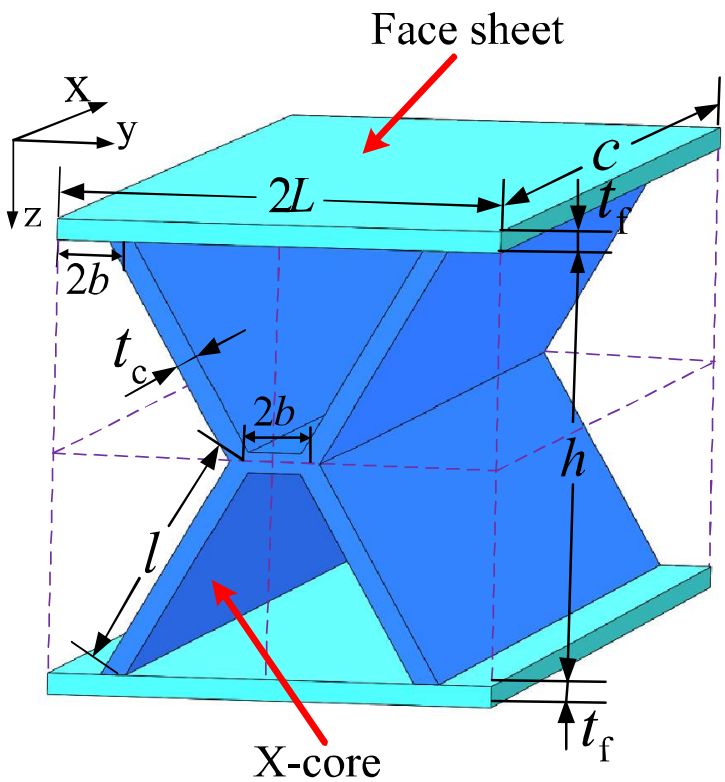

Fig. 3. CAD model and dimensions of the unit cell of the sandwich panel constituted of a central X-core and top and bottom face sheets. 


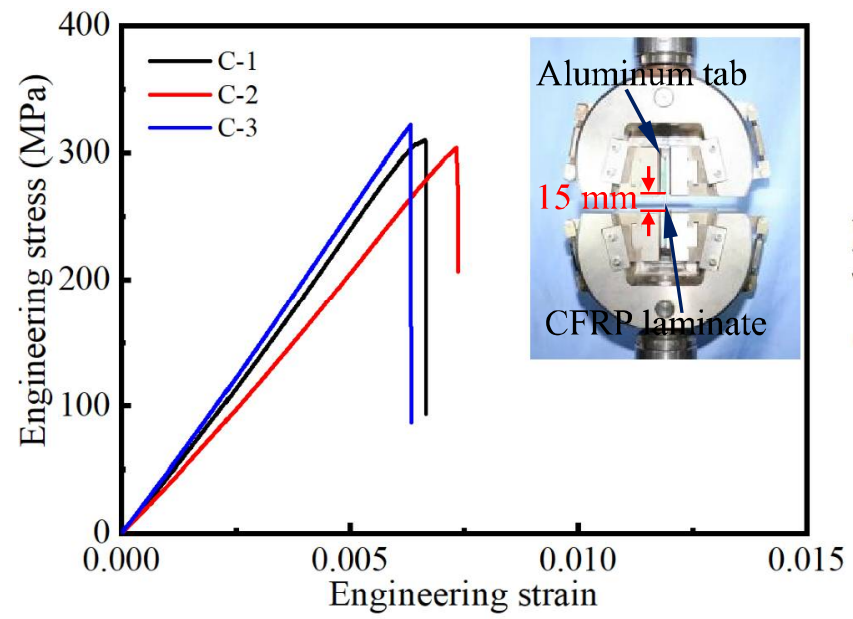

(a)

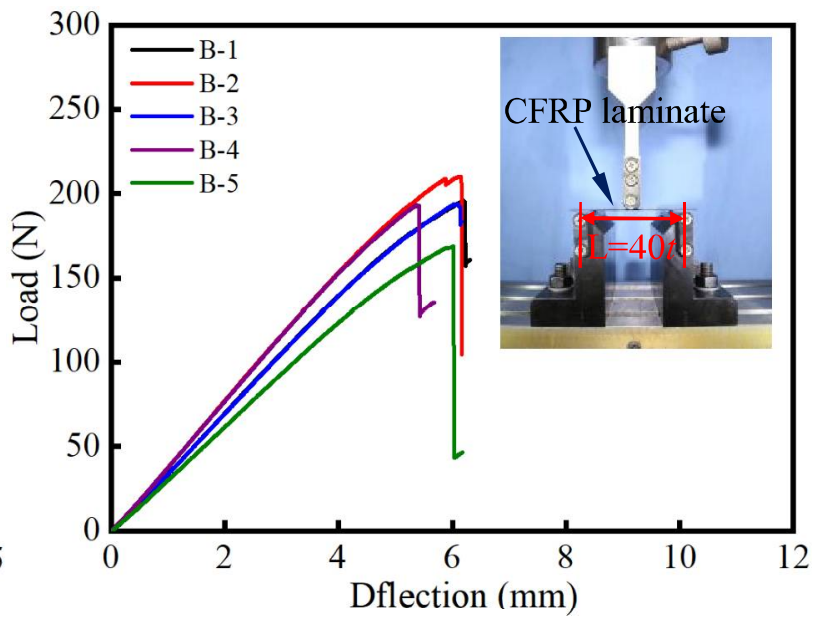

(b)

Fig. 4. (a) Compressive stress-strain curves for CFRP laminates; (b) load-deflection curves of CFRP laminates obtained from the three-point bending tests.

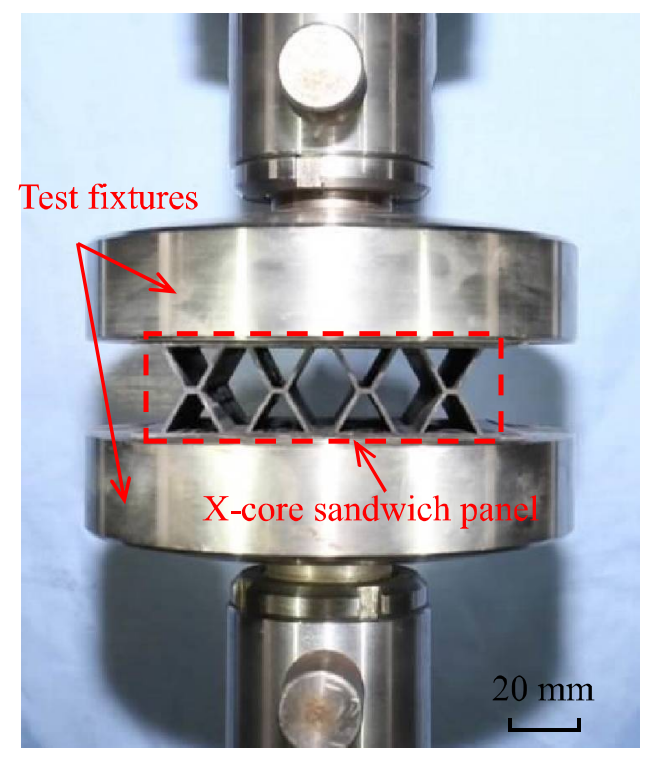

Fig. 5. Experimental setup for the compression tests on the composite X-core sandwich panel. 


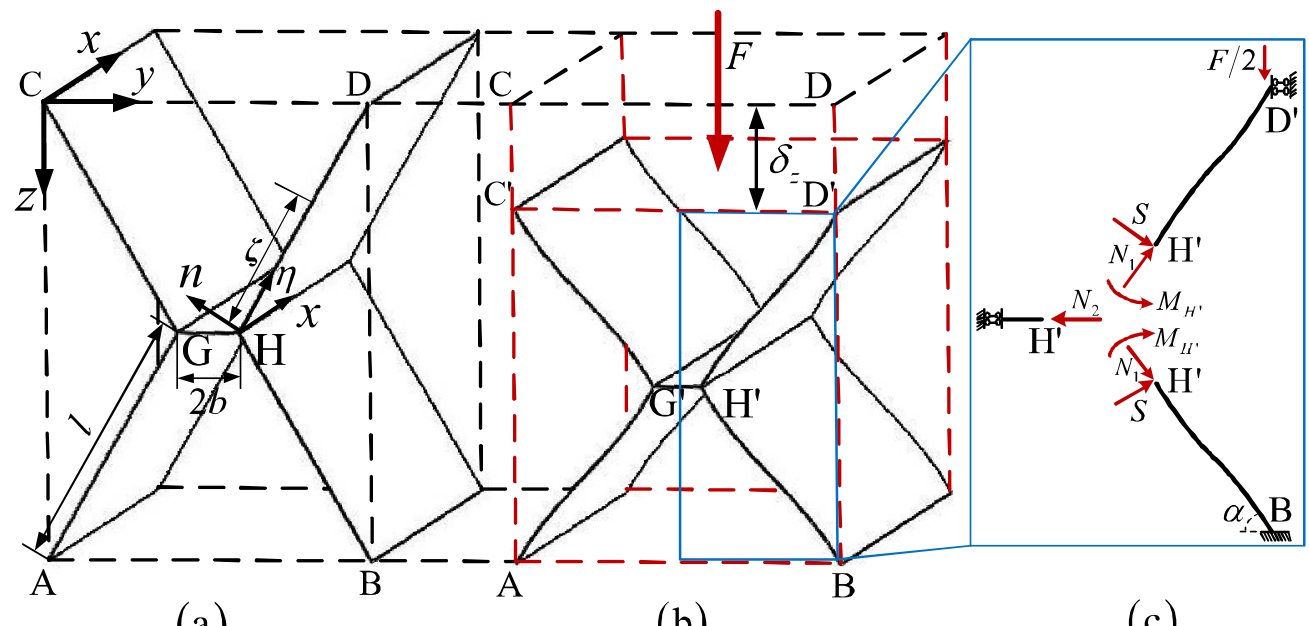

(a)

(b)

(c)

Fig. 6. Schematic of the undeformed (a) and deformed (b) X-core unit cell employed in the analytical model; (c) internal forces and bending moments that develop at the ends of the flanges and web when the unit cell is subjected to compression.

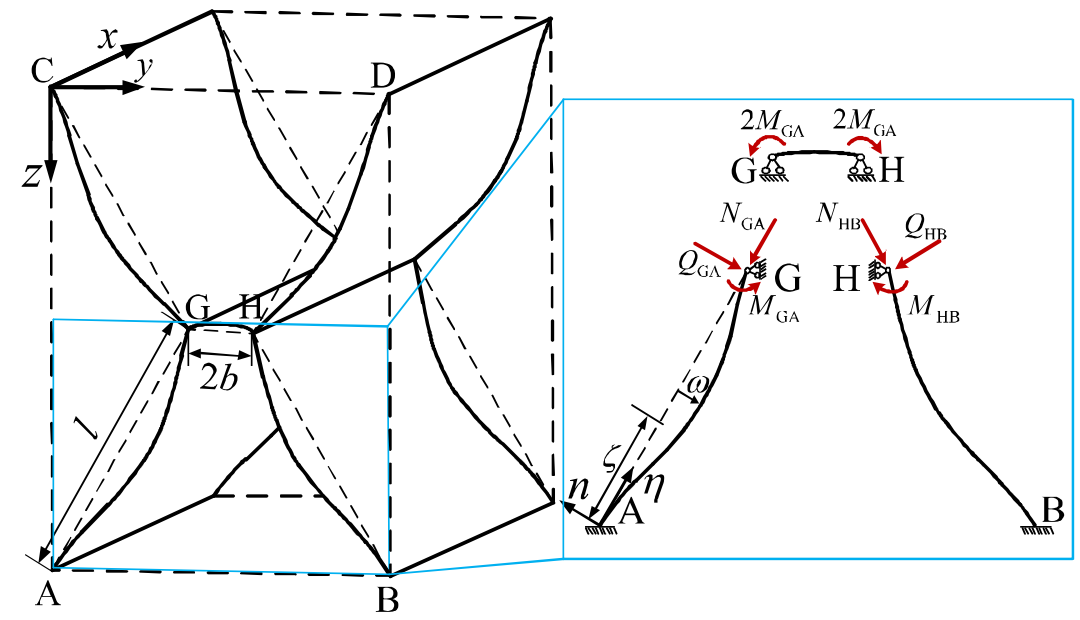

(a)

(b)

Fig. 7. (a) Illustration of the global buckling mode of the X-core unit cell under vertical compression; (b) The internal forces and bending moments that develop during the global buckling mechanism. 


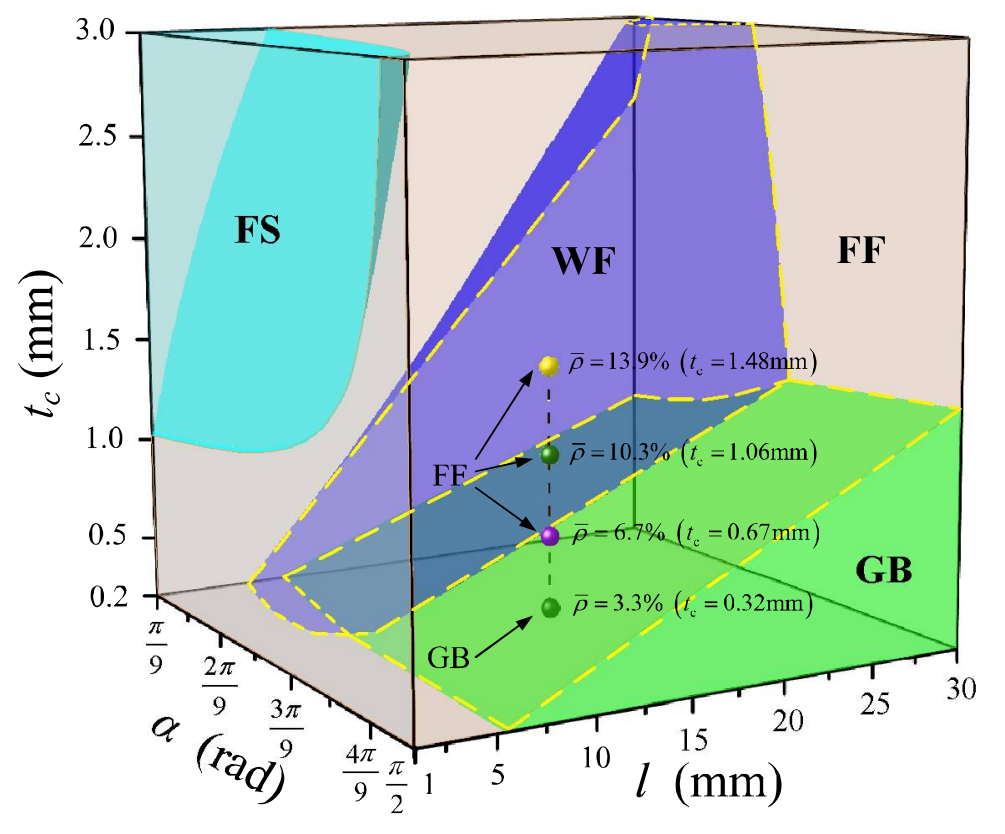

Fig. 8. The failure mechanism map of the X-core sandwich panel subjected to compression. The map shows the four failures modes of flange failure (FF), web failure (WF), flange shear failure (FS) and global buckling (GB) as a function of the three main independent design parameters $l$, $\alpha$ and $t_{c}$. The dots represent the four manufactured samples, characterized by their relative density $\bar{\rho}$ and their failure modes.

(a)

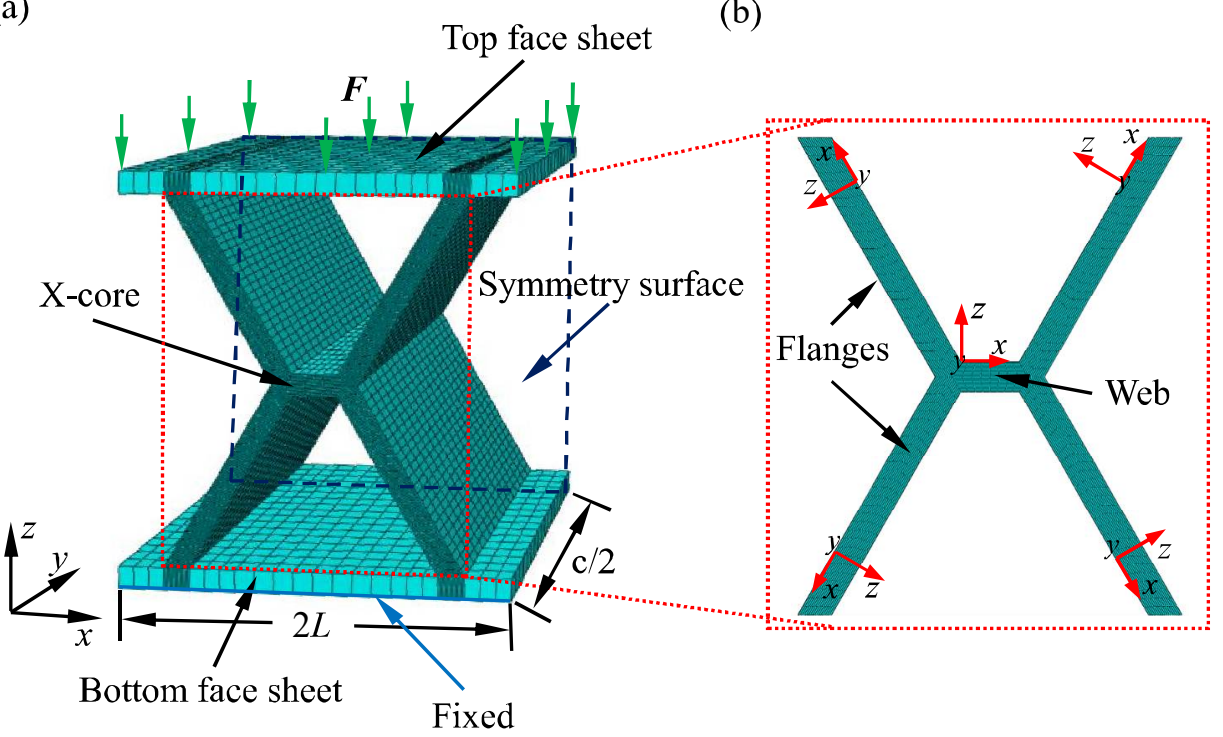

Fig. 9. (a) The FE model of the X-core unit cell with $\bar{\rho}=13.9 \%$ subjected to compression; (b) a detail that shows the local orientation employed to define the material properties of the unit cell struts. 


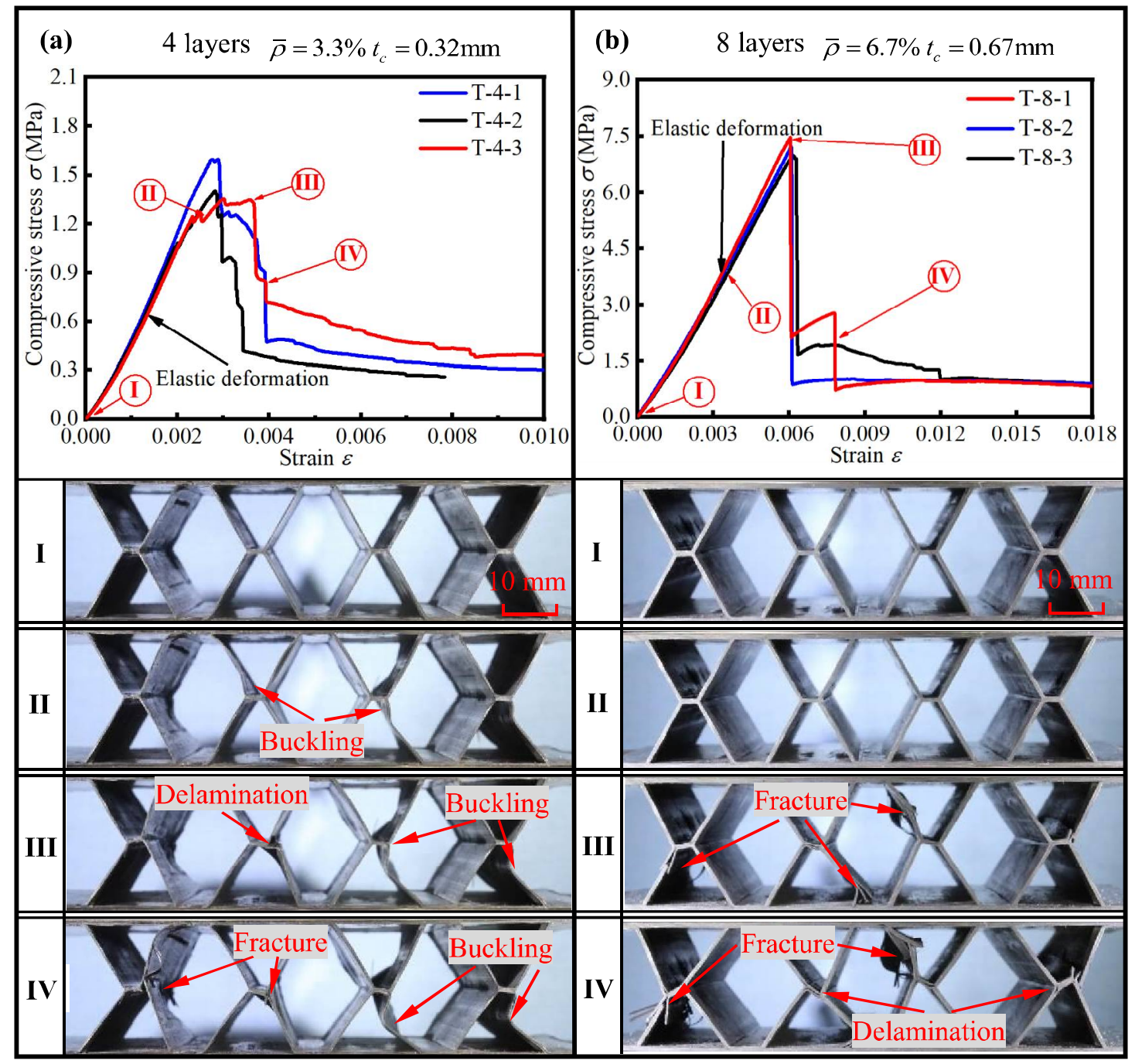

Fig. 10. Experimental engineering stress-strain curves and images of four deformed configurations (I to IV) of X-core sandwich panels with 4 (a) and 8 (b) layers. Failure modes and failure locations are highlighted with red arrows. 


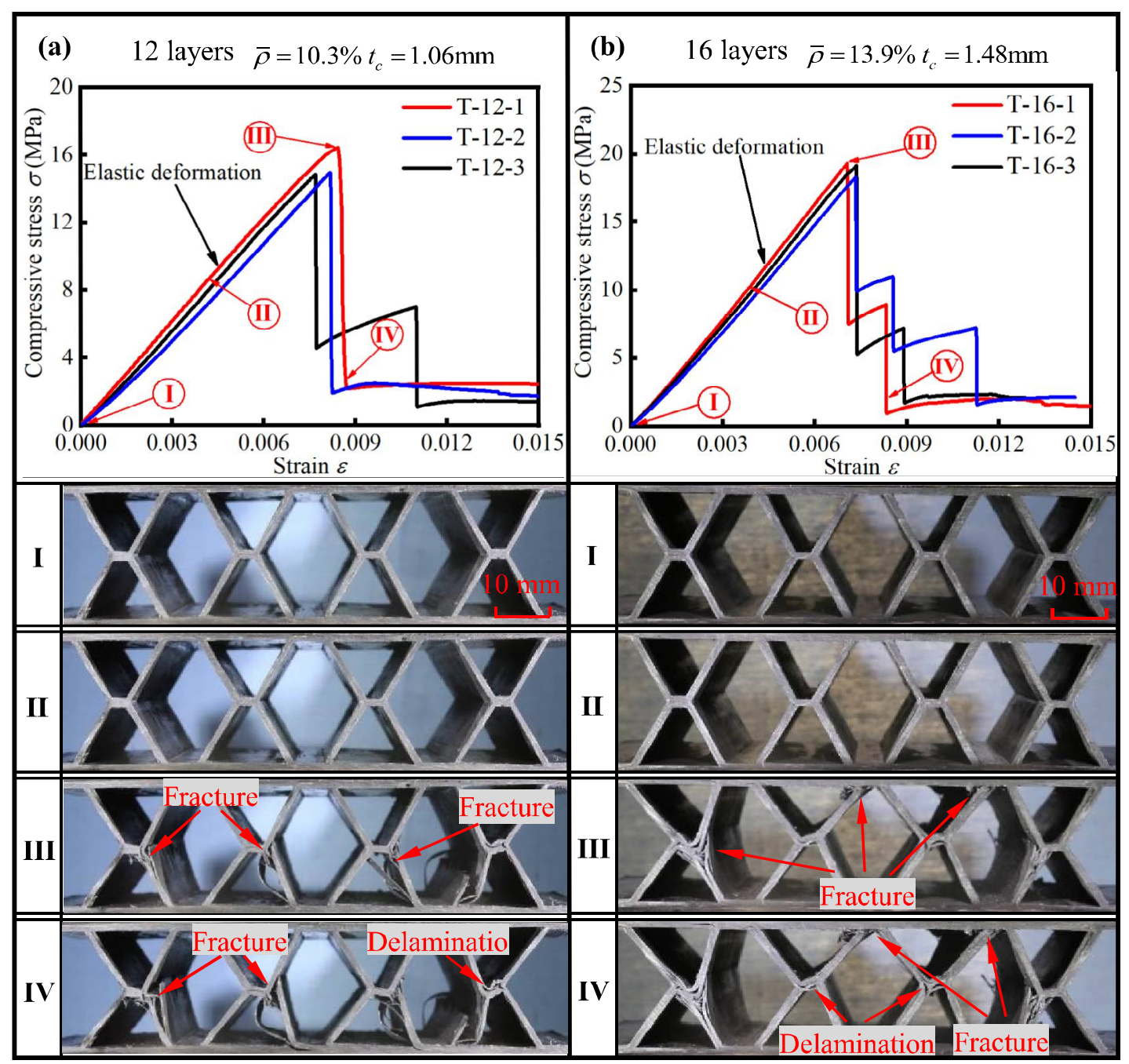

Fig. 11. Experimental engineering stress-strain curves and images of four deformed configurations (I to IV) of X-core sandwich panels with 12 (a) and 16 (b) layers. Failure modes and failure locations are highlighted with red arrows. 


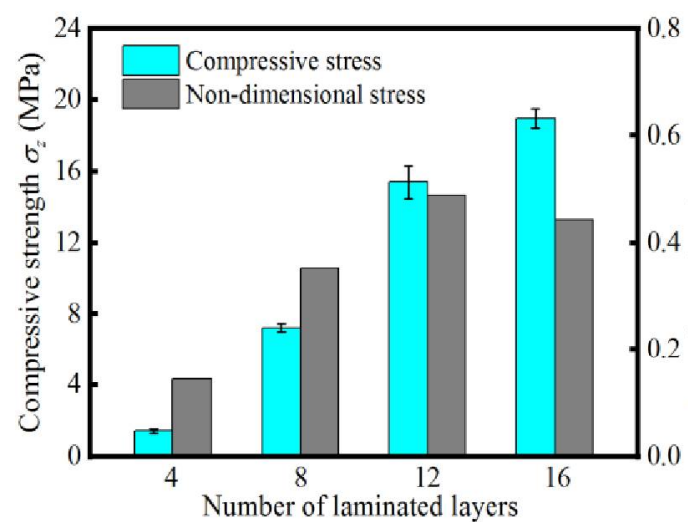

(a)

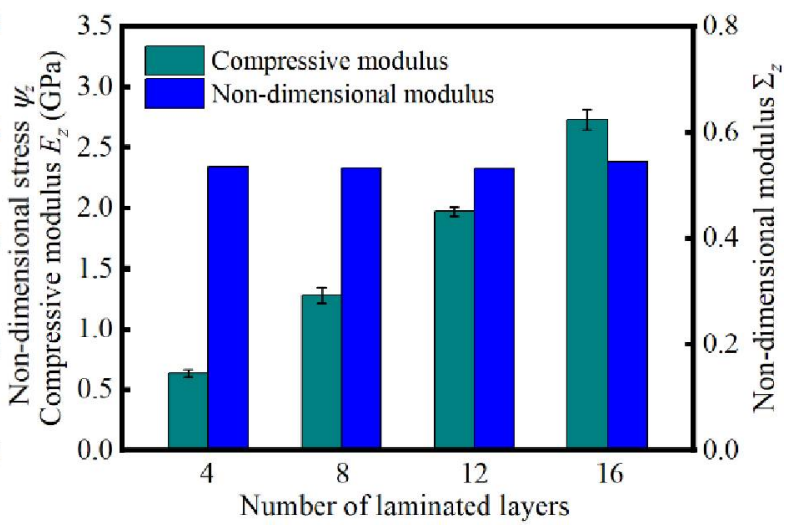

(b)

Fig. 12. (a) The measured compressive strength $\sigma_{z}$ and non-dimensional strength $\Sigma_{z}$ of the $\mathrm{X}$-core sandwich panels as a function of the number of laminated layers; (b) the experimental compressive modulus $E_{z}$ and non-dimensional modulus $\psi_{z}$ of the X-core sandwich panels as a function of the number of laminated layers.

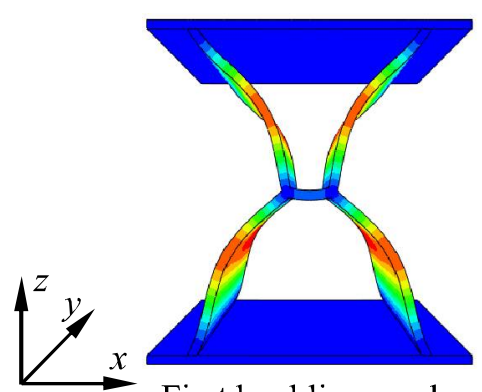

First buckling mode

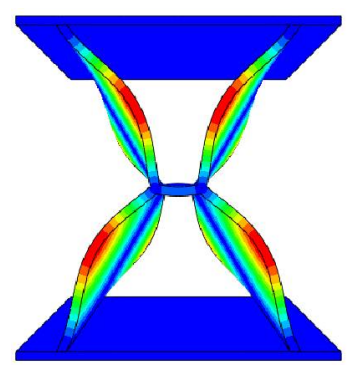

Second buckling mode

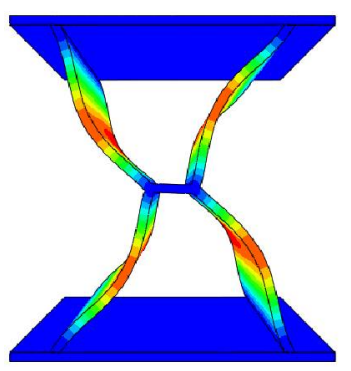

Third buckling mode

Fig. 13. The first three buckling modes of the X-core unit cell, introduced as initial imperfections in the numerical simulations.

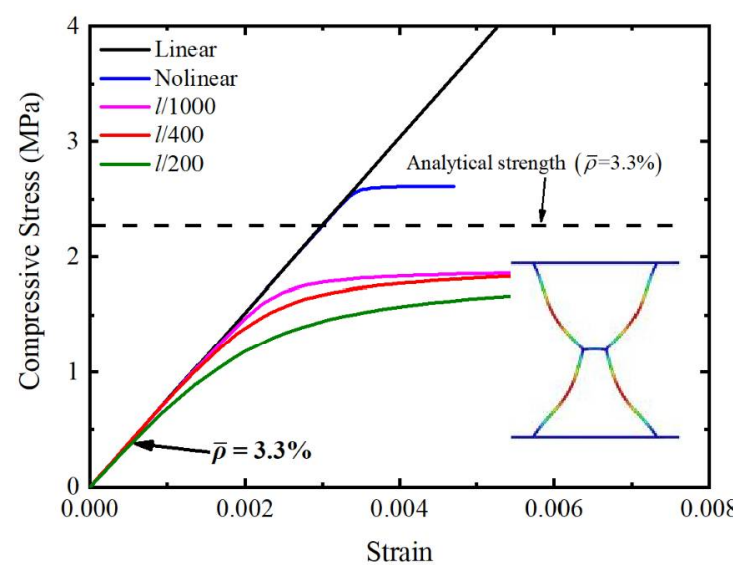

(a)

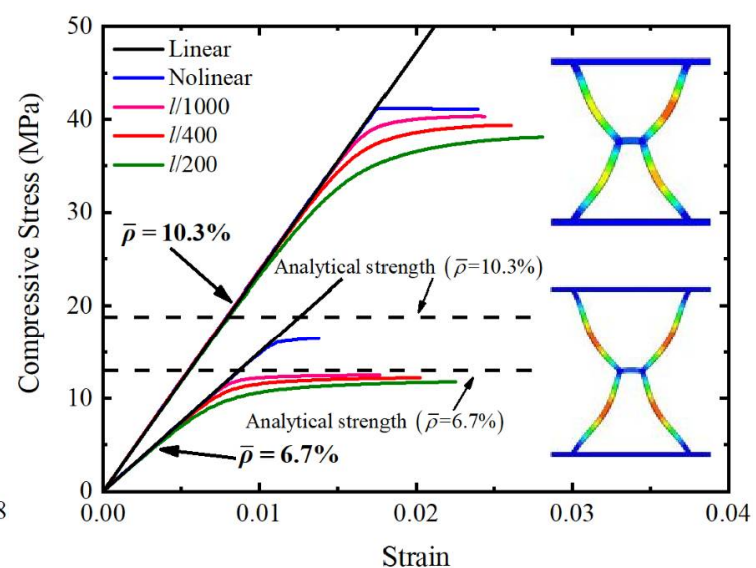

(b)

Fig. 14. The compressive responses of the X-core sandwich panel with different amplitudes of the initial geometric imperfections are compared with the results of linear and nonlinear analyses for unit cell with relative densities $\bar{\rho}=3.3 \%$ (a), $\bar{\rho}=6.7 \%$ and $\bar{\rho}=10.3 \%$ (b). The unit cell analytical strength is reported with a dashed line. The insets show the shape of the unit cells with initial geometric imperfections as the first buckling mode. 


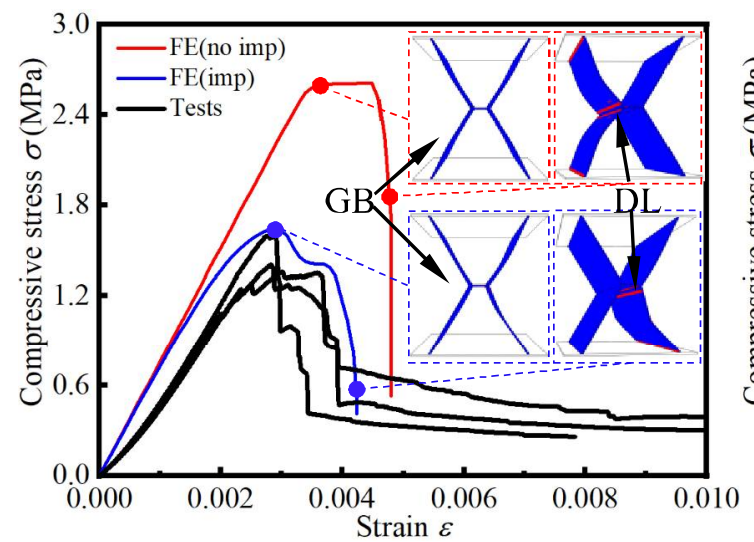

(a)

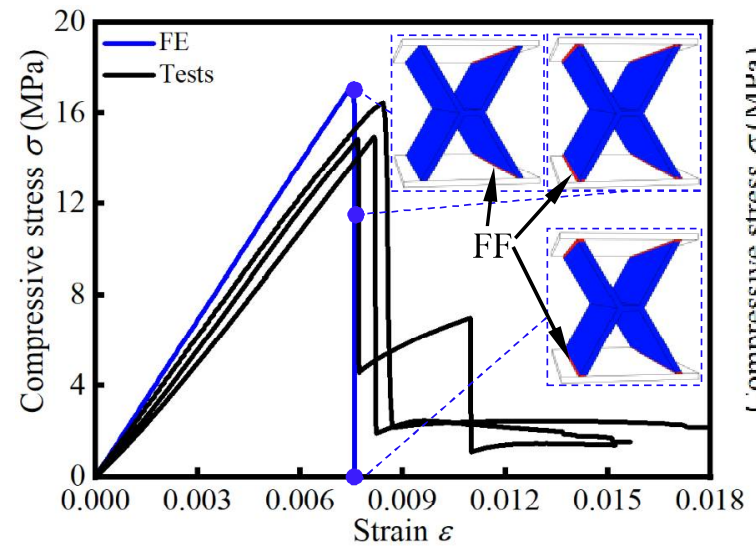

(c)

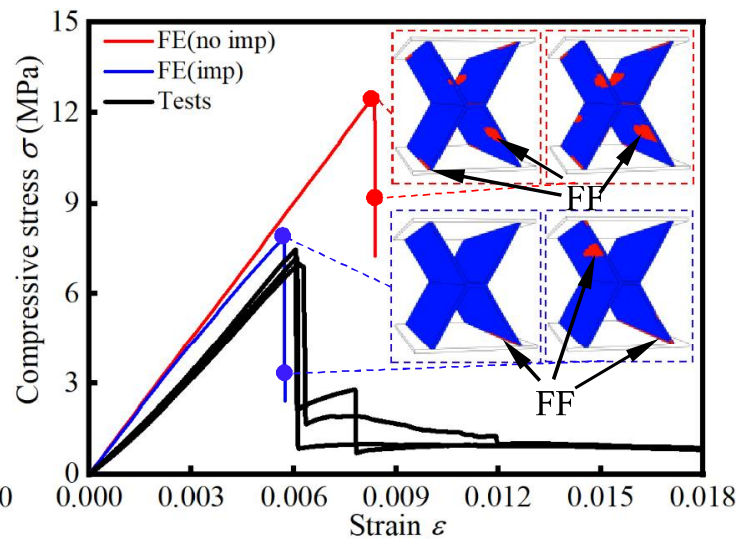

(b)

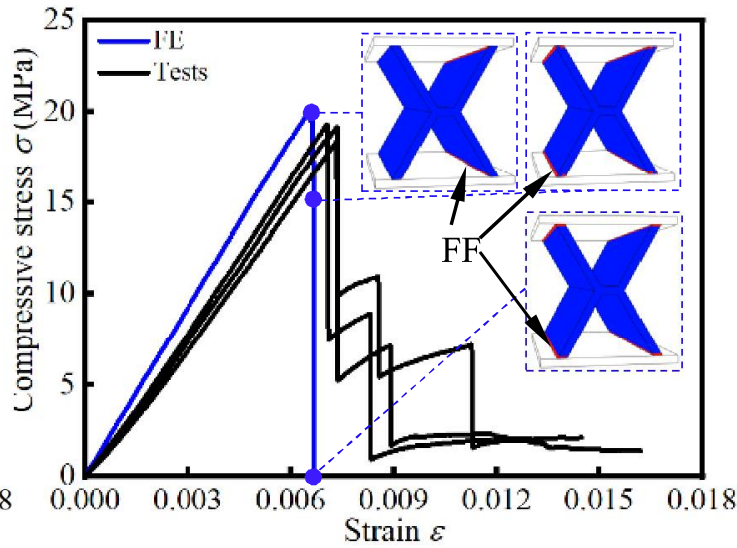

(d)

Fig. 15. Comparison between the numerical predictions and experimental compressive stress-strain curves for X-core sandwich panels with relative densities $\bar{\rho}=3.3 \%$ (a), $\bar{\rho}=6.7 \%$ (b), $\bar{\rho}=10.3 \%$ (c), and $\bar{\rho}=13.9 \%$ (d). For slender geometries (a,b), the finite element response is reported for the unit cell without (labeled as 'no imp') and with an initial geometric imperfection. The insets show the unit cell failure modes: global buckling (GB), delamination (DL) and flange failure (FF). The red regions in the insets indicate the damaged material.

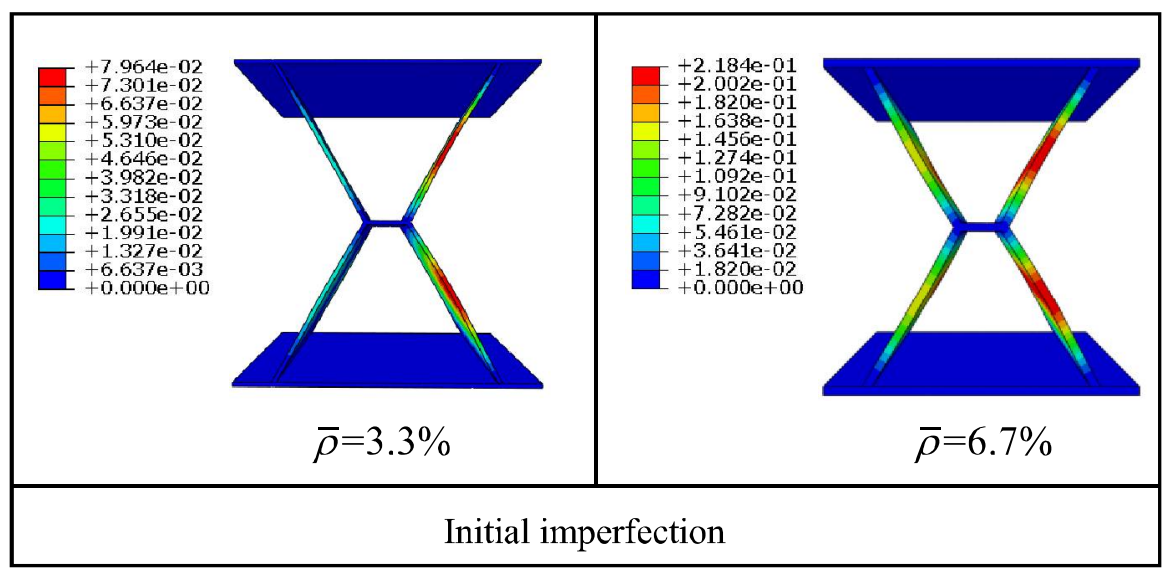

Fig. 16. The representative initial imperfections introdueced in FE(imp) models for X-core sandwich panels with $\bar{\rho}=3.3 \%$ and $\bar{\rho}=6.7 \%$. 

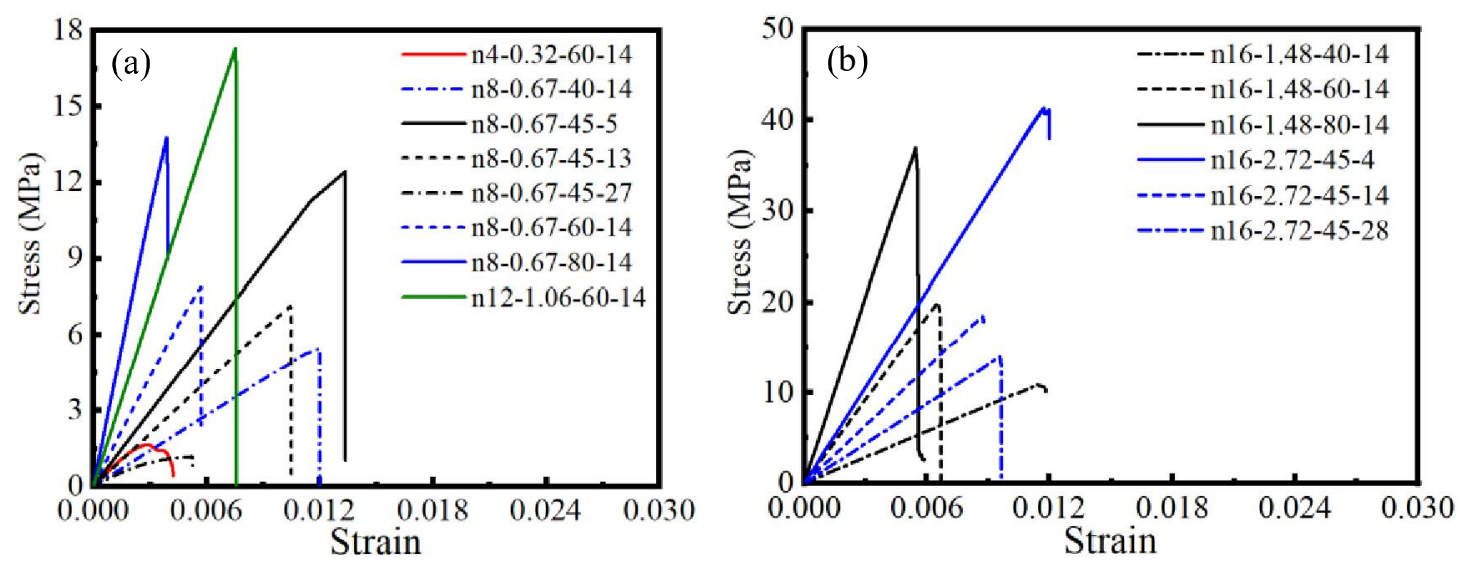

(c)

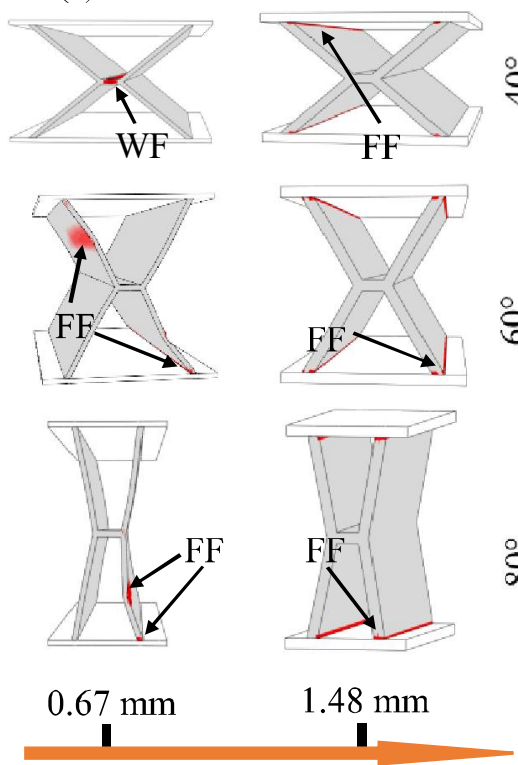

Increase in thickness $t_{c}$

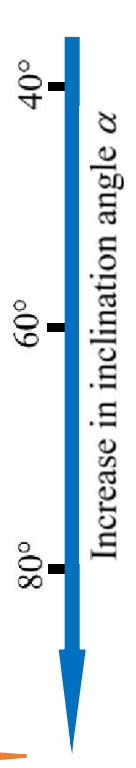

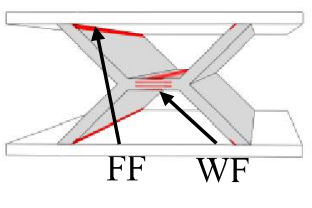
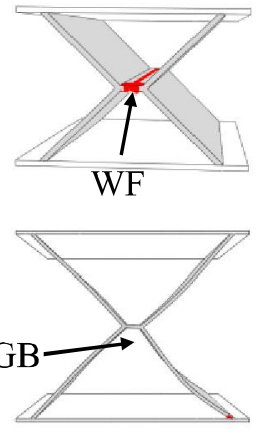

$0.67 \mathrm{~mm}$
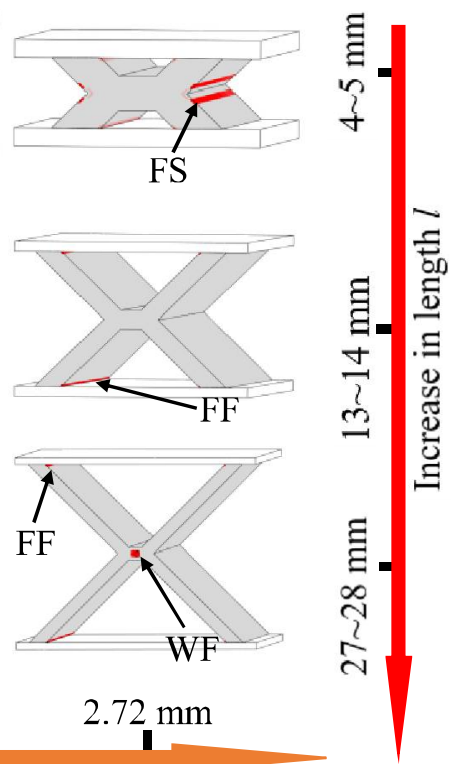

Increase in thickness $t_{c}$

Fig. 17. The numerical stress-strain curves ((a) and (b)) and numerical results of the failure modes (c) for the X-core sandwich panels with different geometric configurations. The insets show the unit cell failure modes: flange failure (FF), web failure (WF), flange shear failure (FS) and global buckling (GB). The red regions in the insets indicate the damaged material.

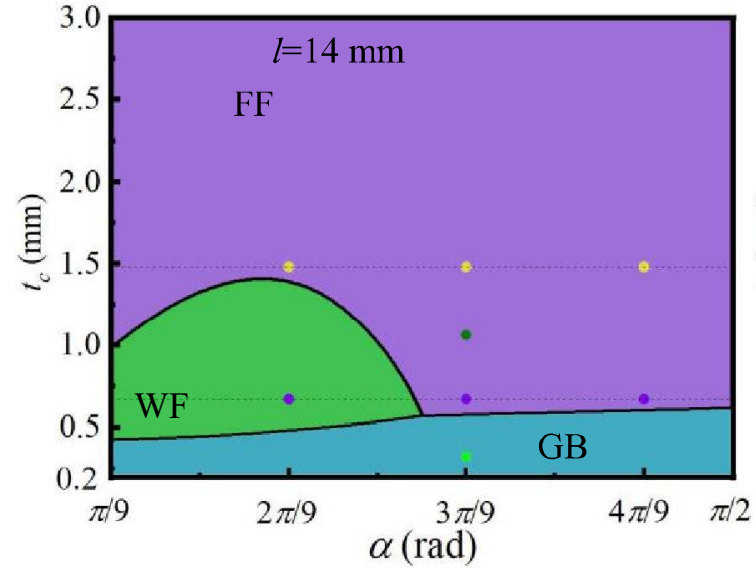

(a)

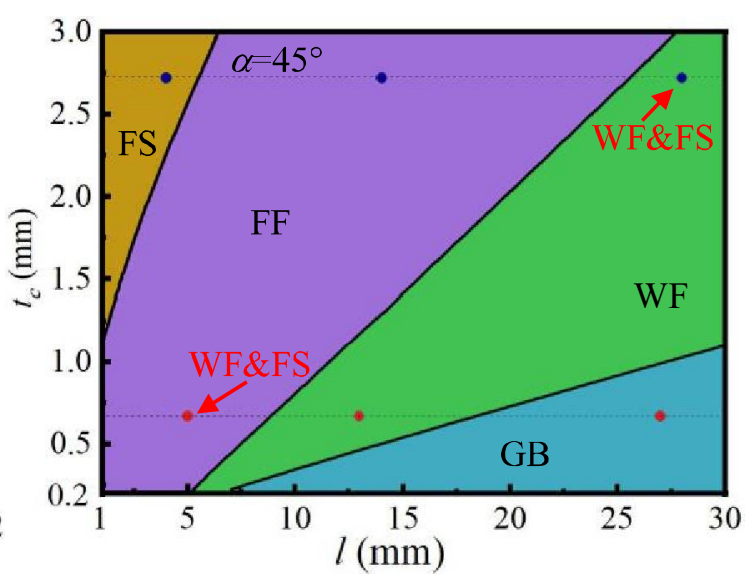

(b)

Fig. 18. The numerical results are compared with the analytical failure mechanism maps. The scatters represent the numerical cases. 
(a)

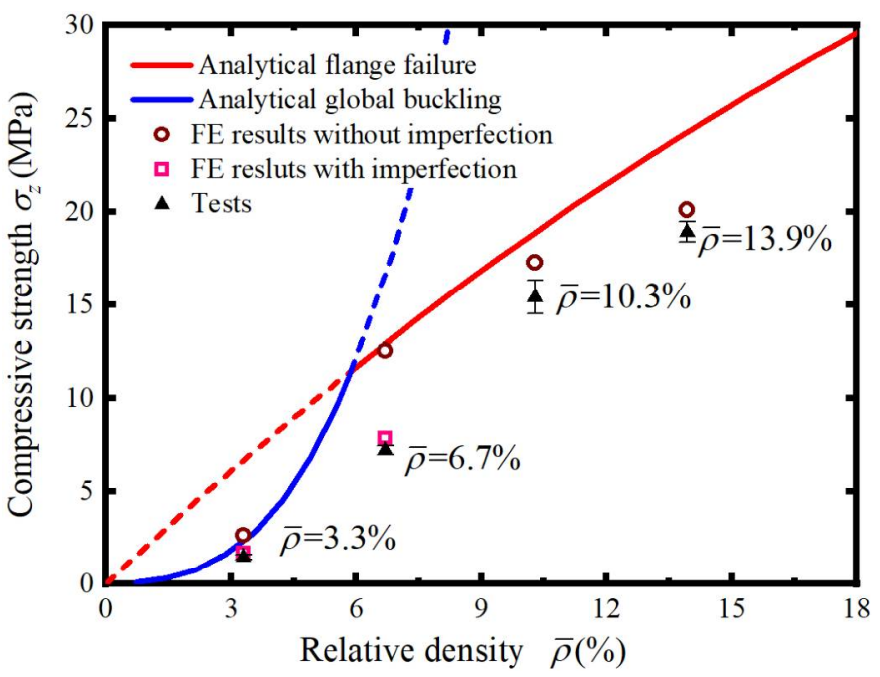

(b)

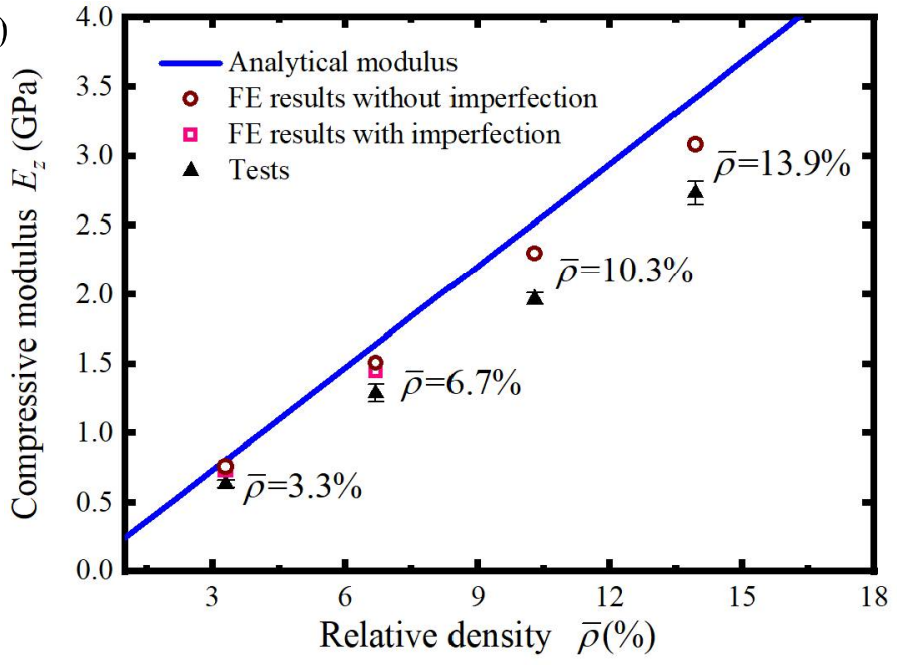

Fig. 19. Compressive strength $\sigma_{z}$ (a) and modulus $E_{z}$ (b) vs. X-core sandwich panel relative density. Analytical predictions are compared with FE results and experimental measures.

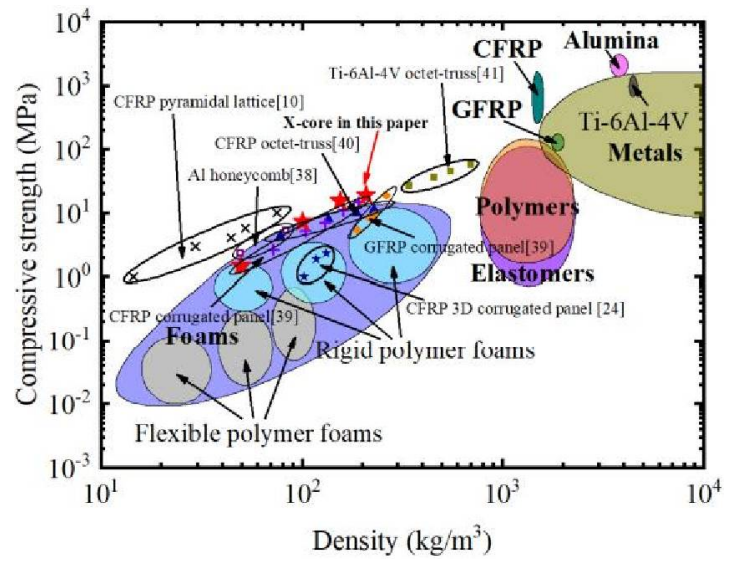

(a)

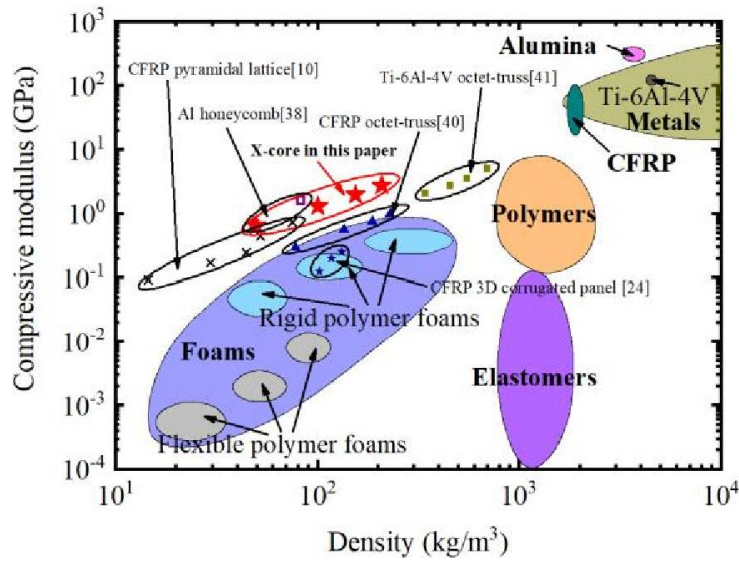

(b)

Fig. 20. The modified Ashby material selection maps of (a) compressive strength against density and (b) compressive modulus against density. 